\title{
Arousal and attention re-orienting in autism spectrum disorders: evidence from auditory event-related potentials
}

\author{
Elena V. Orekhova ${ }^{1,2 *}$ and Tatiana A. Stroganova ${ }^{1}$ \\ ${ }^{1}$ MEG Centre, Moscow State University of Psychology and Education, Moscow, Russia \\ ${ }^{2}$ MedTech West, Sahlgrenska Academy, Gothenburg, Sweden
}

\section{Edited by:}

John J. Foxe, Albert Einstein College of Medicine, USA

\section{Reviewed by:}

Meng-Chuan Lai, University of Cambridge, UK

Edita Poljac, Radboud University Nijmegen, Netherlands

Helen Clery, Institut National de la Santé et de la Recherche Médicale, France

\section{${ }^{*}$ Correspondence:}

Elena V. Orekhova, MEG Centre,

Moscow State University of

Psychology and Education,

Shelepihinskaja embankment 2a,

123290 Moscow, Russia

e-mail: orekhova.elena.v@gmail.com
The extended phenotype of autism spectrum disorders (ASD) includes a combination of arousal regulation problems, sensory modulation difficulties, and attention re-orienting deficit. A slow and inefficient re-orienting to stimuli that appear outside of the attended sensory stream is thought to be especially detrimental for social functioning. Event-related potentials (ERPs) and magnetic fields (ERFs) may help to reveal which processing stages underlying brain response to unattended but salient sensory event are affected in individuals with ASD. Previous research focusing on two sequential stages of the brain response-automatic detection of physical changes in auditory stream, indexed by mismatch negativity (MMN), and evaluation of stimulus novelty, indexed by P3a component,-found in individuals with ASD either increased, decreased, or normal processing of deviance and novelty. The review examines these apparently conflicting results, notes gaps in previous findings, and suggests a potentially unifying hypothesis relating the dampened responses to unattended sensory events to the deficit in rapid arousal process. Specifically, "sensory gating" studies focused on pre-attentive arousal consistently demonstrated that brain response to unattended and temporally novel sound in ASD is already affected at around $100 \mathrm{~ms}$ after stimulus onset. We hypothesize that abnormalities in nicotinic cholinergic arousal pathways, previously reported in individuals with ASD, may contribute to these ERP/ERF aberrations and result in attention re-orienting deficit. Such cholinergic dysfunction may be present in individuals with ASD early in life and can influence both sensory processing and attention re-orienting behavior. Identification of early neurophysiological biomarkers for cholinergic deficit would help to detect infants "at risk" who can potentially benefit from particular types of therapies or interventions.

\section{Keywords: autism spectrum disorders (ASD), arousal, attention re-orienting, sensory modulation, auditory event-} related potentials, cholinergic pathways, nicotine

\section{INTRODUCTION}

Autism spectrum disorders (ASD) are neurodevelopmental disorders that are primarily characterized by impairments in social and communication skills and by repetitive and stereotypical behaviors. Apart from the "core" deficits in social and communication domains, people with ASD show relatively lowlevel abnormalities such as difficulties with regulating arousal level, problems with modulating sensory input, and atypical attention. Depending on the context, attention of individuals with autism may be either overtly over-focused or have no direction whatsoever (Hermelin and O'Connor, 1970; Allen and Courchesne, 2001). Furthermore, they may demonstrate either abnormally elevated or unusually low level of behavioral and autonomic arousal (Kinsbourne, 1987; Hirstein et al., 2001). The other feature of ASD is a frequent occurrence of sensory modulation difficulties manifested in either hyper- or hypo-responsiveness to sensory stimuli (Grandin and Scariano, 1996; Ben-Sasson et al., 2008). The sensory modulation difficulties and attention problems in ASD were observed in different sensory modalities and occur despite the lack of any apparent deficits of the corresponding sensory function.
The role of "low-level" abnormalities of arousal, attention orienting, and sensory responsiveness in people with ASD has been discussed since it had been established by the scientific community that autism has a biological, rather than a social underpinning (Rimland, 1964; Ornitz and Ritvo, 1968; Cohen et al., 1976; Ornitz, 1989). Gradually, the focus of autism research has shifted to investigating higher-order disturbances, such as the "theory of mind" deficit (Baron-Cohen et al., 1985), decreased central coherence (Frith and Happe, 1994), and impaired "mirror neurons" functioning (Williams et al., 2001). Arousal and attention abnormalities are again coming into the focus of autism research as it has become evident that they may precede social symptoms and represent the earliest signs of autism in infants at risk for ASD (Zwaigenbaum et al., 2005; Elison et al., 2013; Elsabbagh et al., 2013).

Co-occurrence of arousal abnormalities, atypical attention, and sensory modulation problems in the same individuals with ASD encouraged researchers to look for causal links between these phenomena. These links are, however, far from clear. BenSasson et al. (2008) suggested that co-occurrence of extreme under- and over-reactive (avoiding) behaviors in children with autism may result from abnormal arousal regulation. Liss et al. 
(2006) and Allen and Courchesne (2001) proposed that both behavioral under- and over-reactivity may be a matter of the individual's attention distribution. Liss et al. (2006) suggested that over-focused attentional style in ASD may be the result of hyperarousal, while Keehn et al. (2013) hypothesized that atypical behavioral arousal regulation in persons with ASD results from early deficits in disengaging attention.

Obviously, it is difficult to draw firm conclusions about the roles of attention and arousal disturbances in ASD neuropsychopathology without looking at the underlying physiological mechanisms. Since basic sensory processes appear to be generally intact in people with ASD, their abnormally reduced or exaggerated responses to environmental stimuli may reflect modulatory influences on information processing in cortical networks. One way to study these modulatory mechanisms would be to look at brain responses to sudden changes in outer environment. The event-related potentials (ERP) and magnetic fields (ERF) have perfect time resolution and may help to investigate neurofunctional deficits in ASD by pinpointing the affected processing stages. In the present paper, we summarize current evidence on arousal and attention orienting abnormalities in ASD within behavioral domain and then discuss studies that applied ERP and ERF techniques to explore relevant physiological deficits. These will include "sensory-gating-type" studies that analyzed "obligatory" auditory ERP components in order to look at preattentive phasic arousal as well as research on two further stages of processing - automatic detection of physical changes in auditory stream indexed by mismatch negativity (MMN) and evaluation of stimulus novelty indexed by the P3a component. Taking into account that the majority of sensory gating, MMN, and P3a studies in ASD used auditory stimuli, we will limit our discussion to the auditory modality. As a whole, the auditory ERP/ERF studies suggest that processing of attended auditory stimuli is either normal or increased in individuals with ASD, while processing of unattended stimuli is usually decreased. We speculate that this is a result of a deficit in the relatively early, pre-attentive arousal processes and that the right hemisphere of the brain may play a particular role in this deficit. Although the pre-attentive arousal deficit was documented in the auditory domain, the supramodal nature of attention and sensory modulation problems in ASD (Murray et al., 2005; Leekam et al., 2007; Bonneh et al., 2008) infers that abnormal pre-attentive arousal is present across sensory modalities.

In conclusion, we will speculate that the difficulties in attention re-orienting and sensory modulation as well as abnormal physiological arousal are related to a deficit in the nicotinic branch of the cholinergic arousal system that is well documented in ASD (Deutsch et al., 2010; Anand et al., 2011). Our focus on the cholinergic system is explained by its commonly acknowledged role in attention re-orienting and arousal (Everitt and Robbins, 1997; Robbins, 1997; Sarter and Bruno, 2000; Greenwood et al., 2005, 2009, 2012; Sarter et al., 2005; White and Yee, 2006; Giessing et al., 2012). Apart from cholinergic abnormalities, individuals with ASD demonstrate prominent abnormalities of GABAand glutamatergic neurotransmission (Oblak et al., 2010, 2011; Fatemi et al., 2013). There are complex mutual interactions between these neurotransmitters and cholinergic pathways (see e.g., Albuquerque et al., 2009) that are to be addressed by the future neural modeling studies of ASD.

\section{DIFFICULTIES WITH REGULATING AROUSAL, ATTENTION, AND SENSORY PROCESSING IN ASD AROUSAL}

The term "arousal" was originally used to describe both behavior and physiological activity, including its cortical and autonomic components (Lacey, 1967). Arousal can be subdivided into tonic and phasic. The tonic arousal describes relatively slow fluctuations in the energetic arousal state during sleep and wakefulness, while phasic arousal responses indicate the organism's energetic reaction to specific stimulus events (Combs and Polich, 2006). Tonic and phasic arousal are interdependent and produce strongly overlapping activation of a predominantly rightward-lateralized frontal, parietal, thalamic, and brain-stem network (Sturm and Willmes, 2001).

Fluctuations in arousal level during sleep and wakefulness are mediated by multiple arousal systems of the brain (Robbins, 1997; Dringenberg and Vanderwolf, 1998; de Lecea et al., 2012). These systems differ in respect to the primary neurotransmitter, are characterized by some specificity of cortical and subcortical projections, and have different functions in arousal-like processes (Robbins, 1997). The coeruleo-cortical noradrenalin (NA) system mediates brain capacity to maintain "alerting" to salient external stimuli. The mesolimbic and mesocortical dopamine (DA) systems play a role in the activation of output, whether cognitive or motor in nature, and are critically important for executive functions. The cholinergic $(\mathrm{ACh})$ system mediates regulation and allocation of processing resources as well as attention and memory processes and is involved in attention re-orienting in space (Witte et al., 1997; Giessing et al., 2012; Greenwood et al., 2012). The serotonergic (5-HT) system serves to dampen the actions of all other systems by promoting behavioral inhibition and cortical de-arousal. Different arousal systems interact closely. For example, the classically recognized cortical activating effects of ascending NA system depends, to a significant extent, on a basal forebrain cholinergic input to the cortex (Dringenberg and Vanderwolf, 1998; Berntson et al., 2003).

Thus, arousal is a complex phenomenon and different neurofunctional abnormalities may contribute to its dysregulation in ASD. There are strong arguments for the presence of abnormalities of cholinergic (Deutsch et al., 2010; Anand et al., 2011) and serotoninergic (Harrington et al., 2013) systems, while the evidence for the role of dopaminergic and noradrenergic systems is less conclusive (Canitano and Scandurra, 2011).

Various aspects of behavioral and autonomic indicators of arousal are affected in ASD. Sleep disturbances are commonly observed in children with ASD and correlate with autism severity (Tudor et al., 2013). Tonic arousal, understood as a degree of vigilance or alertness during wakefulness, was suggested to be either abnormally increased (Hutt et al., 1964, 1965), decreased (Rimland, 1964), or unstable, possibly due to excessive or fluctuating ascending activation in the brain (Hermelin and O'Connor, 1970; Kinsbourne, 1987). Phasic arousal is also atypical in people with ASD, with either decreased or increased reactions to stimuli (van Engeland, 1984; Hirstein et al., 2001; Schoen et al., 2008). 
The most widely used measures of autonomic arousal are the tonic skin conductance level (SCL) and spontaneous and stimulus-related fluctuations in electro-dermal activity (EDA). Schoen et al. (2008) have found that some children with autism had high SCL (high tonic arousal) associated with higher than normal EDA magnitudes, faster latencies, and slower habituation; while others had low SCL (low tonic arousal) linked with lower EDA magnitudes, slower latencies, and faster habituation. The authors concluded that children with autism represent a heterogeneous population in terms of autonomic arousal.

One factor that contributes to the large inter-individual variability of SCL and EDA in individuals with ASD may be the excessive context-dependent fluctuation of these measures. In study of Hirstein et al. (2001) children with autism mainly had higher than normal baseline SCL and high-amplitude EDA. In the majority of the children, however, SCL and EDA dropped below the values observed in normal control groups as soon as they became involved in self-stimulatory activities (provoked by putting their hands in a bowl with beans).

van Engeland (1984) have noted that children with autism were often electrodermally nonresponsive to the first stimulus in a row of sounds, thus resembling schizophrenic patients. As such abnormal non-responsiveness was observed only to the first stimulus in a row, the authors concluded that it might be a statedependent phenomenon, possibly reflecting abnormal allocation of attention.

Difficulties with arousal regulation may be present in children with ASD very early in life, well before the social symptoms of autism become evident. The incidence of sleep problems during the first 2 years of life is higher in children with ASD than in either typically developing children or those with mental retardation without autism (Dahlgren and Gillberg, 1989). Increased irritability and proneness to distress have been observed in toddlers later diagnosed with ASD (Bryson et al., 2007).

Interestingly, indications of atypical arousal regulation have been found even in 4 months-old graduates of neonatal care unit (ICU), who later went on to ASD (Karmel et al., 2010; Cohen et al., 2013). These infants had an abnormally high preference for more arousing visual stimulation, which reliably differentiated them from the ICU graduates without ASD, irrespective degree of their CNS injury. Moreover, in participants without significant brain damage the preference for higher rates of stimulation at 4 months correlated with lower social competence at 3 years, but only in those with initially abnormal auditory brain-stem potentials (Cohen et al., 2013). This combination of brain stem and arousal abnormalities suggests that damage to the brain stem that leads to arousal dysregulation is a risk factor for autism.

To sum up, atypical arousal and/or problems with arousal regulation are already present in individuals with ASD in their infancy. In older children, the predominant type of arousal abnormality may vary between different individuals, as well as within the same individual, and depends on this individual's immediate state. Arousal dysregulation manifests itself in two distinct modes of functioning. The first mode is characterized by elevated tonic arousal, anxiety, and difficulties to concentrate attention. The second mode is reflected in reduced tonic arousal, self-stimulatory activities, and decreased awareness of surrounding outside of the current attention focus.

\section{ATTENTION}

Attention abnormalities in children with autism have been already described by Leo Kanner, who observed not only a lack of attention to people in these pediatric patients, but also admitted that many of them were "oblivious to all but immediate focus of attention" (Kanner, 1968). Hermelin and O'Connor (1970) have noted that attention in autistic individuals is either overtly over-focused or has no direction whatsoever. Since these early descriptive studies, the narrow "spot-light" focus of attention and difficulties with re-directing attention were repeatedly reported in scientific literature (Kinsbourne, 1991; Allen and Courchesne, 2001; Ames and Fletcher-Watson, 2010) as well as in personal accounts of individuals with autism (Grandin and Scariano, 1996). Importantly, problems with re-directing attention in autism are evident in both social and nonsocial domains (Townsend et al., 1996; Dawson et al., 1998; Harris et al., 1999; Zwaigenbaum et al., 2005; Baranek et al., 2013), suggesting a generalized deficit in re-orienting. Moreover, these attention difficulties are rather specific for autism, as they discriminate children with autism not only from typically developing children but also from children with developmental delay without autism (Dawson et al., 1998).

Different psychophysical paradigms have been applied to elucidate the nature of attention abnormalities in ASD (see Ames and Fletcher-Watson, 2010 for review). Many studies used modifications of an experimental paradigm developed by Posner et al. (1984). According to Posner, attention can be subdivided into three relatively independent modules related to alerting, orienting, and executive control. Posner's paradigm is applicable to measuring alerting and orienting modules. The orienting module includes processes of disengagement, shifting, and reengagement. Participants are usually presented with visual stimuli appearing on a computer screen to their left or to their right and asked to press a button in response to the "target" stimulus. The target is usually preceded by a warning visual signal (i.e., "cue"). Spatial position of the cue relative to the target as well as time interval between the cue and the target are manipulated across the paradigms. There are usually 4 types of spatial "cue and target" combinations: no cue, spatially non-informative, congruent, and non-congruent. In the no-cue condition, the target is not preceded by a cue altogether. Spatially non-informative or neutral cues may be bilateral or appear in the center of the screen and provide the subject with a non-spatial alert of a coming target. Congruent or valid cues are presented in the same place where the target will appear. Finally, non-congruent or invalid cues are shown in the location opposite to the target. Neutral cues alert the subjects and decrease reaction time to the target relative to the "no-cue" condition. Fastest responses are observed in case of validly cued targets, because attentional resources are directed to the cued location in advance of the target appearance. Invalid cue, on the other hand, prolongs subject's reaction time because attention has to be disengaged and re-oriented from the invalidly cued location to a validly cued one. Thus, effectiveness of different attention orienting processes can be measured by 
comparing subjects' reaction times between the four cue-target combinations. For example, alerting is measured by the difference in reaction time between "no-cue" and "neutral cue" conditions. The orienting-shifting score can be assessed by comparing reaction time between "neutral" and "congruent" cues. Finally, attention disengagement efficacy is measured by comparing reaction time between "congruent or valid" and "non-congruent or invalid" conditions.

The other task that is often used to measure attention disengagement is the "gap-overlap" task. In the "gap" condition, the central fixation stimulus disappears before presentation of the peripheral target stimulus. In the "overlap" condition, the central fixation stimulus remains on the screen during target presentation. In order to execute saccade to the peripheral target under the "overlap" condition, participants have to disengage attention from the central stimulus, while such disengagement is not necessary in the "gap" condition. In this case disengagement is measured as a difference in saccade latency between overlap and gap conditions.

Both Posner and "gap-overlap" paradigms were applied to evaluate alerting and orienting in ASD. No apparent abnormalities in alerting have been found in people with ASD using a modification of Posner paradigm (Keehn et al., 2010). Some studies have found that children with ASD were either generally slower to shift attention (Keehn et al., 2010) or performed less number of rapid attention shifts (Landry and Bryson, 2004) as compared to the typically developing children. Others reported in participants with ASD greater than normal number of "express" saccades with extremely short reaction time to the target stimuli during the "overlap" condition in the "gap-overlap" task (Kawakubo et al., 2004), or demonstrated less than normal differences in saccade latency between the gap and overlap conditions (van der Geest et al., 2001). These latter findings are indicative of engagement rather than disengagement problems in ASD.

Since disengagement is a function of initial engagement, it can be altered through the manipulation of stimuli (Marshall, 2011). A certain level of initial engagement by (i.e., interest to) the central fixation stimulus is, therefore, necessary in order to reveal the disengagement deficit in ASD. The studies that probably fulfilled this requirement did find attention disengagement problems in ASD using gap-overlap tasks (Landry and Bryson, 2004; Kawakubo et al., 2007; Elsabbagh et al., 2013).

The majority of studies that used Posner's-type paradigms also reported the disengagement deficit in people with ASD (Casey et al., 1993; Wainwright-Sharp and Bryson, 1993; Townsend et al., 1996; Harris et al., 1999; Renner et al., 2006). Importantly, in order to reveal this disengagement deficit, the delay between the cue and the following target stimulus in the Posner's paradigm had to be long enough to allow for successful engagement of attention by the preceding cue (Wainwright-Sharp and Bryson, 1993). Generally, the slow disengagement of attention is one of the most robust attention deficits found in ASD (Ames and Fletcher-Watson, 2010).

Remarkably, problems with shifting attention and, particularly, with disengagement of attention were found even in infants at high risk for autism (Zwaigenbaum et al., 2005; Elison et al., 2013; Elsabbagh et al., 2013) and predicted later diagnosis. It has been widely discussed in the literature that deficits in earlydeveloping attentional systems have a profound effect on the long-term prognosis of a child with autism. General impairments in orienting to social as well as nonsocial sensory stimuli may cause a cascade of developmental consequences for later-developing social communicative functions, including joint attention and language development (Mundy and Neal, 2001; Mundy and Jarrold, 2010; Baranek et al., 2013). In line with this hypothesis, a recent study has shown that impairments in attention disengagement in children with ASD correlate with higher severity of core autism symptoms (Bahrick and Todd, 2013).

The term "disengagement" introduced by Posner et al. (1984) closely overlaps with the term "re-orienting" used by Corbetta et al. (2008). Corbetta and colleagues have delved more closely into activity of neural networks responsible for automatic shifts of attention to unattended but salient targets. On the cortical level, the system subserving re-orienting/disengagement includes temporo-parietal junction (TPJ) and ventral frontal cortex (VFC), which in turn is comprised of certain parts of middle frontal gyrus, inferior frontal gyrus, frontal operculum, and anterior insula (Corbetta et al., 2008; Corbetta and Shulman, 2011). These cortical areas in combination with subcortical arousal systems constitute a strongly rightward-lateralized ventral attentional network (VAN).

At the neural level, problems with attention disengagement/reorienting in ASD are likely to relate to a failure of the VAN, a deficiency at subcortical levels preceding VAN activation or a break in communication between the two. Taking into account that VAN strongly overlaps with cortical areas involved in social cognition (Corbetta et al., 2008), its dysfunction in ASD would also be in line with a co-occurrence of attention orienting and social deficits in these disorders.

It should be noted, however, that problems with attention orienting are not unique for autism, but were also observed in young people with Williams syndrome who do not display the joint attention or social deficits associated with ASD (Lincoln et al., 2002). Results of Lincoln et al. (2002) warn that attention re-orienting/disengagement deficit in early development is, by itself, not sufficient to cause later social impairments and that specific neural factors underlying the attention disengagement abnormalities in ASD may play the key role.

To sum up, the reduced ability to disengage (a previously engaged) attention is one of the most consistently found cognitive deficits in individuals with ASD from infancy onwards. Notably, this behavioral deficit is not specific to social stimuli, suggesting a general failure of attention networks. Such failure appearing early in life may have an important contribution to abnormal development of social cognition.

\section{MODULATION OF SENSORY INPUT}

High incidence of sensory modulation problems, including both hyper- and hypo-responsiveness to stimuli of different modalities is observed in individuals with ASD across their life span (O'Neill and Jones, 1997; Harrison and Hare, 2004; Crane et al., 2009; Wiggins et al., 2009) and differentiates them from both neurotypical individuals and those with developmental delay. The importance of abnormal sensory sensitivity in ASD 
neuro-phenotype has been recently recognized by including it into the new edition of the Diagnostic and Statistical Manual of Mental Disorders (DSM-5) as a group of clinically relevant symptoms. The two sensory response patterns (hyper-responsiveness and hypo-responsiveness) may coexist in the same individual and be expressed in a context-dependent manner (Hirstein et al., 2001; Baranek et al., 2006). The co-occurrence of extreme underand over-reactive behaviors in children with ASD may indicate a common etiology underpinning poor sensory modulation, such as abnormal attention (Liss et al., 2006) or arousal regulation (Ben-Sasson et al., 2008).

It has been suggested that non-responsiveness to sensory stimuli may particularly strongly contribute to development of autism via an interruption of basic orienting responses that are foundational for the development of joint attention skills (Baranek et al., 2013). Liss et al. (2006) analyzed co-occurrence of sensory and attention disturbances (over-focusing) in a big sample of children with ASD and have found that subjects characterized by overfocused attention style were also characterized by high over- and under-reactivity and had the most severe symptoms of autism, although not necessarily lower IQ. In a recent study, Baranek et al. (2013) have shown that low sensory responsiveness to both social and non-social stimuli in young children with ASD was associated with low mental age and predicted lower levels of joint attention and language. Watson et al. (2011) also reported in children with autism a significant association of hypo-responsiveness with the severity of social-communicative symptoms, while did not find such an association for hyper-responsiveness.

To sum up, co-occurence of sensory modulation difficulties, arousal regulation problems, and atypical attention in people with ASD suggests the presence of a common underlying physiological deficit. The non-responsiveness and failure to re-orient attention to novel or important (e.g., social) cues seem to be especially closely linked to the core features of autism. Below we review EEG and MEG studies that investigated different stages of information processing in individuals with ASD that are relevant for the understanding of their attention re-orienting problems.

\section{PROCESSING OF NOVELTY AND CHANGE IN ASD: EVIDENCE FROM AUDITORY ERP AND ERF STUDIES}

Pre-attentive detection of stimulus salience or novelty is mandatory for automatic re-orienting of attention. In this section we will review ERP/ERF studies investigating pre-attentive and attentionrelated automatic processing of physically or temporally novel or deviant acoustic events in ASD. We will focus on the ERP/ERF components that are affected by stimulus novelty or change in stimuli stream. The earliest brain-derived auditory ERP component that displays these properties is P50 (Skinner et al., 2004; Nakagawa et al., 2013). We will start the discussion by looking at the latter ERP components (P3a and MMN), since these components have been the focus of the majority of the ERP/ERF studies in ASD.

\section{AUTOMATIC PROCESSING OF NOVELTY AND CHANGE IN THE “ODDBALL PARADIGM"}

Attention re-orienting to novel stimulus is preceded by automatic detection of sensory change. Neural correlates of both change detection and attention re-orienting are often investigated using auditory oddball paradigm. In case of the "regular oddball," the frequent "standard" stimuli are occasionally substituted by rare "deviants" that are different from the standard by pitch, duration, or other acoustic or semantic properties. Subjects either respond to the rare deviants (e.g., with a button press) or passively attend to the auditory stimulation stream. In the latter case they often watch an unrelated video presented in order to reduce boredom and/or distract attention from the auditory stimulation. Stimuli are usually presented with short $(<1 \mathrm{~s})$ intervals in order to preserve the echoic memory trace of the preceding sound and to facilitate automatic comparison.

$\mathrm{MMN}$ is a component of electrical/magnetic brain response elicited at $100-200 \mathrm{~ms}$ after the onset of change and is thought to signify a brain process responsible for change detection. It is measured as a difference wave between responses to deviant and standard stimuli. MMN is maximal over fronto-central scalp areas and is thought to be generated by the sources at superior temporal gyri (Jaaskelainen et al., 2004) and, possibly, also at frontal areas (Deouell, 2007). Large MMN amplitudes are associated with greater stimulus differences and accurate discrimination of these differences, suggesting that $\mathrm{MMN}$ is a cortical index of sound-discrimination accuracy (Naatanen et al., 2007).

P3a is associated with involuntary orienting of attention and is usually measured in a passive version of the oddball paradigm in response to unattended deviant stimuli. P3a is recorded over frontal and parietal cortical areas around $280 \mathrm{~ms}$ post-stimulus and is thought to be generated by distributed cortical sources comprising the attention re-orienting network (Mantini et al., 2009). "Novelty P3" - a component similar to P3a-is elicited in response to "novel" stimuli presented in a "novelty oddball" paradigm (Friedman et al., 2001). In this modification of the paradigm, P3 is measured in response to the highly deviant and/or unique novels presented among the more perceptually similar standards and deviants. Because the subject is not informed about these initially novel events, the "novelty oddball" procedure mimics more closely the real-world involuntary attentional capture by novel or unexpected events. Although novelty P3 and P3a are elicited by distinctly different stimuli during quite different task circumstances, they may reflect the output of a similar configuration of neural sources (Friedman et al., 2001). Both $\mathrm{MMN}$ and novelty-P3/P3a reflect functioning of neuronal mechanisms critically important for processing of novel or deviant events. MMN signifies initial detection of deviancy, whereas P3a is related to involuntary attention orienting and evaluation of those events for subsequent behavioral action (Friedman et al., 2001).

The majority of the MMN studies in ASD subjects used passive oddball paradigm while subjects watched a silent movie or read a book. The wide spectrum of obtained results probably reflects characteristics of the particular samples, stimulation parameters, and details of the experimental procedures. Many of the studies reported higher MMN amplitudes (Ferri et al., 2003; Lepisto et al., 2005, 2006, 2007; Korpilahti et al., 2007; Kujala et al., 2007, 2010) and/or shorted latencies (Gomot et al., 2002, 2011; Ferri et al., 2003; Lepisto et al., 2005; Korpilahti et al., 2007; Kujala et al., 2007) in individuals with ASD. These findings correspond well with behavioral data on superior auditory discrimination 
observed in these individuals (Mottron et al., 2000; Bonnel et al., 2003; O'Connor, 2012), their auditory hypersensitivity (Stiegler and Davis, 2010; Lucker, 2013), and their general hypersensitivity to change. Indeed, shorter MMN latencies in children with ASD correlated with a low tolerance of change (in place, time, people, food, and clothes) (Gomot et al., 2011). Some researchers, however, reported unremarkably normal MMN in ASD (Kemner et al., 1995; Ceponiene et al., 2003). Moreover, some EEG (Seri et al., 1999; Jansson-Verkasalo et al., 2003; Kujala et al., 2005, 2007; Lepisto et al., 2006; Andersson et al., 2013) and two available MEG studies (Tecchio et al., 2003; Cardy et al., 2005) have found decreased MMN amplitudes and/or prolonged MMN latencies in ASD participants. Interestingly, two studies investigating MMN to prosody deviants in Asperger's syndrome both reported significant but opposite findings. Children with Asperger's syndrome had higher MMN amplitudes and shorter latencies than the age-matched "neuro-typical" controls (Korpilahti et al., 2007), whereas adults with Asperger's syndrome had lower MMN amplitudes and longer latencies (Kujala et al., 2005).

Age, IQ, parameters of the stimulation (e.g., "speechness" of the sound), nature of stimulus change (e.g., pitch, intensity, duration)—all may have their roles in the difference of MMN findings reported by different authors. These roles are, however, far from being clear, because opposite MMN findings were reported for similar auditory stimuli and for groups of participants comparable in terms of their age and IQ. For example, impaired detection of deviance in ASD reflected by reduced amplitude and/or increased latency of MMN was observed in children (Seri et al., 1999; Jansson-Verkasalo et al., 2003; Cardy et al., 2005) and adolescents/adults (Tecchio et al., 2003; Kuhl et al., 2005; Andersson et al., 2013); in those with normal IQ (Jansson-Verkasalo et al., 2003; Lepisto et al., 2006; Andersson et al., 2013) and with mental retardation (Seri et al., 1999; Tecchio et al., 2003); in response to speech stimuli (JanssonVerkasalo et al., 2003; Kujala et al., 2005) and in response to tones (Seri et al., 1999; Jansson-Verkasalo et al., 2003; Tecchio et al., 2003; Lepisto et al., 2006; Andersson et al., 2013). Enhanced detection of change in ASD reflected by increased amplitude and/or shortened latency of MMN has also been reported in children (Gomot et al., 2002, 2011; Ferri et al., 2003; Lepisto et al., 2005, 2006; Korpilahti et al., 2007; Kujala et al., 2010) and adults (Kujala et al., 2007; Lepisto et al., 2007); in those with normal or nearly-normal IQ (Lepisto et al., 2005, 2006, 2007; Korpilahti et al., 2007; Kujala et al., 2010) and with mental retardation (Ferri et al., 2003; Gomot et al., 2011); in response to speech (Korpilahti et al., 2007; Lepisto et al., 2007; Kujala et al., 2010) and non-speech (Gomot et al., 2002, 2011; Ferri et al., 2003; Lepisto et al., 2005; Kujala et al., 2007) stimuli.

We propose that such variability in findings might, at least partly, reflects the degree of subject's attentiveness to the stream of the test stimuli vs. his/her attention to the surroundings (e.g., to a movie used to keep the subject busy during the auditory experiment) or even to the subject's internal feelings or thoughts. In its turn, direction of attention during passive oddball paradigm could be potentially modulated by a number of factors, such as attractiveness of the movie for the particular age/IQ, quality of the auditory test stimuli (e.g., speech, non-speech), the level of anxiety in unfamiliar experimental settings, etc.

Although MMN is believed to be relatively insensitive to the direction of subject's attention, as it is present even in sleep (Ibanez et al., 2009), the direction of attention to/away from the auditory stimulation does influence MMN amplitude in healthy children (Gomes et al., 2000). Moreover, amplitudes of the auditory MMN and P3a are modulated by the difficulty of the interfering visual task (Yucel et al., 2005; Rissling et al., 2013), thus reflecting the impact of available attention resources on physiological processes related to automatic change detection or involuntary attention switching. Considering limited attention capacities (narrow attention focus, difficulties with attention reorienting) in people with ASD, direction of their attention to the auditory stream may have a disproportionately large role for the MMN and the P3a responses when compared to neurotypical individuals. For example, the presence of an interfering auditory perceptual stream (e.g., a movie with a sound track, irrelevant to the auditory oddball stimulation) may deteriorate processing of test auditory stimuli in children with ASD to a stronger degree than in children without ASD.

Indeed, two studies applying sound stimuli over an acoustic background of a simultaneously presented movie, have found a strongly reduced MMN in response to either tone (Dunn et al., 2008) or speech (Kuhl et al., 2005) stimuli in children with ASD. These finding are especially convincing taking into account quite representative samples of these studies (Dunn et al., 2008: 34 ASD and 34 control subjects; Kuhl et al., 2005: 29 ASD and 15 controls). Dunn with coauthors repeated the study with a smaller sample of participants using both "passive/sound track" and "active" oddball conditions. The latter task modification required subjects' attention to the test stimuli and their manual response. In this second experiment, participants with ASD displayed normal MMN in the "active" condition, but, again, lacked MMN in the "passive/sound track" condition, thus supporting the role of limited attention recourses in MMN generation in ASD.

If MMN is evoked by salient stimulation, it is normally followed by a P3a wave. Similar to the MMN results, the P3a findings in ASD also range from virtual absence to increased amplitude and shorter latency. The early studies have shown that P3a is strongly reduced in children with ASD in response to taskirrelevant highly deviant novel sounds (non-speech noises) in the "novelty oddball" paradigm (Courchesne et al., 1984; Kemner et al., 1995). Courchesne et al. (1984, 1985) have also found in individuals with ASD decreased amplitude of the anterior negative component following P3a to "novels" and peaking at $\mathrm{Cz}$ with latency between 600 and $1000 \mathrm{~ms}$ (i.e., A/NCz/800). This component resembles re-orienting negativity later described by Schröger and Wolff (1998) and may be linked to re-orienting from taskirrelevant "novels" toward task-relevant aspects of stimulation. Therefore, similarly to the reduced $\mathrm{P} 3 \mathrm{a}$, the reduced $\mathrm{A} / \mathrm{NCz} / 800$ might reflect diminished processing of unattended novel sounds in ASD.

The studies mentioned above employed an active oddball task, where subjects were required either to push a button in response to the deviant stimuli (Courchesne et al., 1984) or to count them 
(Kemner et al., 1995). Similarly to the previous MMN findings (Kuhl et al., 2005; Dunn et al., 2008), the abnormally deceased P3a response to the task-irrelevant "novel" sounds observed in individuals with autism in these studies may reflect their limited attention resources, rather than a failure to process novelty. Specifically, the presence of a task might facilitate linking of sequential sound elements together into a segregated auditory stream of "standards and deviants" thus placing a unique novel sound outside of this attended stream. Therefore, while focusing on a particular task-relevant stimulation, people with ASD may fail to detect even salient acoustic events that do not belong to this attended stream.

The majority of other studies investigating P3a in ASD used a passive "regular oddball" paradigm. Among these, the studies that used speech stimuli often reported decreased P3a amplitudes (Ceponiene et al., 2003; Lepisto et al., 2005, 2006, 2007), while those applying non-speech sounds reported increased P3a amplitudes and/or shortened latencies (Gomot et al., 2002, 2011; Kujala et al., 2007; Lepisto et al., 2007). Some researchers have suggested that the orienting deficit reflected in P3a reduction in autism might be speech-sound specific (Ceponiene et al., 2003). Whitehouse and Bishop (2008), however, have shown that reduced $\mathrm{P} 3 \mathrm{a}$ in response to speech deviants in individuals with ASD can be better explained by their generally reduced attentiveness to the stream of speech, rather than an inability to orient attention to novel speech sounds. The authors presented highfunctioning children with autism with two modifications of the oddball paradigm. In the first case, the speech non-unique "novels" (vowel /i/) were presented among the stream of non-speech standard and deviant stimuli. In the second case, the complex non-unique "novel" tone was imbedded among the standard and deviant speech sounds (vowels /a/ and /i/). Importantly, the "novels" in the study of Whitehouse and Bishop (2008) were not unique, i.e., they were repeated many times and therefore probably did not pop-out of the stimulation stream to the same degree as the unique and highly perceptually different stimuli applied by Courchesne et al. (1984) and Kemner et al. (1995). In different trials, the subjects were asked either to ignore the stimuli (passive condition) or to respond to the deviants (active conditions). P3a was measured as a difference between novel and standard stimuli. Under passive condition, P3a in ASD children was abnormally reduced in response to tone novels presented in the speech stream, but it was abnormally increased in response to speech novels presented among non-speech stimuli (both $p$ 's $<0.05$ ). No deficit, however, was found in the "active oddball" versions of the task when children attended to the stimuli. The authors concluded that the children with high-functioning autism were able to allocate attention to a novel speech sound if it was embedded in a sequence of non-speech auditory stimuli, but used top-down inhibition to attenuate responses to repeated streams of speech. Whatever the neural mechanisms underlying reduced processing of unattended stimuli in ASD are, the results of Whitehouse and Bishop clearly demonstrate the critical role of sustained attention to the sensory stream in the reported P3a findings in ASD. They also show that since the P3a abnormalities in ASD strongly depend on the second-order cognitive factors, they can hardly represent the primary deficit.
The role of attention in hypo- vs. hypersensitivity to change in ASD is further supported by functional Magnetic Resonance Imaging (fMRI) findings of Gomot et al. (2006, 2008). In the first study (Gomot et al., 2006), children were presented with a passive auditory novelty oddball task while watching a video. The participants with high-functioning autism activated "novelty detection network" in response to the novel stimuli significantly less than their age- and IQ-matched peers, and the maximal group difference was seen in the TPJ region. In a later study using the same stimuli (Gomot et al., 2008), researches asked participants to respond by a button press as soon as they heard a "strange" novel sound. In this active paradigm the children with high-functioning autism activated a few cortical regions, including inferior parietal area near TPJ, significantly greater than the control children. These fMRI findings in ASD were accompanied by shortened reaction times, showing that the higher brain activation was adaptive and advantageous for their behavioral response.

To sum up, the ERP/ERF studies focusing on two sequential stages of the brain response to the novel or deviant stimuliautomatic detection of physical changes indexed by MMN and evaluation of stimulus novelty indexed by the P3a componentfound in individuals with ASD either increased, decreased or normal processing. These results suggest that individuals with ASD are generally able to detect changes in the stimulation stream when this stream is in the focus of their attention. Prominent problems arise when the deviant or novel stimuli appear in the presence of a strongly interfering task or stimulation (i.e., outside focus of attention). In this case, individuals with ASD may lack P3a observed in non-ASD comparison groups and demonstrate reduced amplitude of MMN. The fact that presence and direction of the MMN and P3a abnormalities in ASD depend on the context of stimulus presentation suggests that they do not reflect the primary deficits, but are rather preceded by a failure of even earlier triggering processes.

\section{EARLY PRE-ATTENTIVE AROUSAL IN SENSORY GATING PARADIGM}

The "sensory gating" paradigm that is specifically focused on pre-attentive arousal stages of auditory processing usually investigates "obligatory" ERP components in response to clicks. The pairs of clicks ("S1" and "S2") separated by a short within-pair interval are presented with much longer inter-pair intervals. In adults, the so-called "obligatory" component P1 (also called P50), with latency of 50-80 ms, and N1, with latency of approximately $100 \mathrm{~ms}$, decrease in amplitude with stimulus repetition, reflecting dampened processing of repetitive auditory input ("gating-out"). Usually, this inhibitory gating-out process is measured by a P50 S1/S2 amplitude ratio (but see also Kisley et al., 2004). The larger response to $\mathrm{S} 1$, on the other hand, reflects bottom-up arousal (Skinner et al., 2004) and/or initial orienting response (Atienza et al., 2001) caused by a rare and poorly predictable S1 sound, i.e., "gating in" (Boutros and Belger, 1999; Brenner et al., 2009).

The P50 component of AEP reflects ascending activation of the cholinergic arm of the reticular activation system (RAS) and is closely linked to pre-attentive arousal processes (Skinner et al., 2004). According to Skinner there are a few properties 
of P50 that support its association with RAS activity. Firstly, P50 is present during waking and rapid eye movement (REM) sleep, but is dampened during deep slow wave sleep (i.e., it is present when the cortex is activated). Secondly, it is mediated, at least in part, by cholinergic branch of arousal system. There is evidence for involvement of nicotine receptor-mediated cholinergic activity in the generation of P50 response to the S1 (Adler et al., 1999; Leonard et al., 2002). Thirdly, it rapidly habituates at stimulation rates greater than $2 \mathrm{~Hz}$ (i.e., it is sensitive to the "temporal novelty") (Buchwald et al., 1992) and is sensitive to changes in stimulation (Nakagawa et al., 2013). Its generation in secondary auditory areas that receive input from non-lemniscal thalamo-cortical pathways (Howard et al., 2000) is also in line with its close involvement in arousal processes (Skinner et al., 2004).

In children, the P50 (P50m in MEG) response to click is followed by another positive deflection of potential (Stroganova et al., 2013) (Figure 1) or magnetic field (Orekhova et al., 2013) (Figure 2) with latency of about $90-140 \mathrm{~ms}$ (P100 or P100m in $\mathrm{MEG})$. The presence of the "P1 complex" comprising two positive waves (P50 and P100) thus distinguishes child response to the auditory clicks from the adult P50-N100 waveform. Similarly to that in P50, the strong attenuation of P100 with stimulus repetition suggests its link with arousal-like processes (Orekhova et al., 2012, 2013; Stroganova et al., 2013). The P100/P100m response to binaural or contralateral monaural S1 click is normally of higher amplitude in the right hemisphere. Such rightward lateralization may, at least partly, reflect greater involvement of the right hemisphere in sound localization, arousal, and attention processes (Hadlington et al., 2004; Ofek and Pratt, 2004; Howard and Poeppel, 2009; Nakagawa et al., 2013; Teshiba et al., 2013), although anatomical factors may also play a role (Shaw et al., 2013).

The vertex-positive P1 is thought to originate from extralemniscal projections to cortical pyramidal neurons in lower layer III and layer IV of the belt and parabelt areas of the auditory cortex (Eggermont and Ponton, 2003) and reflect bottom-up nonspecific modulation of these areas (Kral and Eggermont, 2007). During childhood and adolescence the later part of the P1 complex (mainly represented by $\mathrm{P} 100$ ) is gradually canceled out in the surface EEG by the later maturing N100 component (Ponton et al., 2002; Eggermont and Ponton, 2003). In adult studies these waves are usually not separated and are therefore addressed to as P1 or P50. Even in adults, however, some researchers identified two positive waves contributing to $\mathrm{P} 1$, which were called $\mathrm{P} 1 \mathrm{a}$ and P1b (Yvert et al., 2001). Conceivably, the adult P1a and P1b components correspond to the child's P50 and P100. In children the whole positivity between $50-140 \mathrm{~ms}$ is often mistakenly considered to be a developmental analog of the adult P50. However, the distinction between P50 and P100 in children is important, because these components may reflect different processes and, as we discuss later, are differently affected in ASD.

The sensory gating studies typically do not control for effects of direction of the subject's attention. It has been shown, however, that directing attention to the auditory stimuli does result in increase of the P1/S1 amplitude (White and Yee, 2006; Yee et al., 2010; Gjini et al., 2011). Therefore, if the effect of re-orienting is

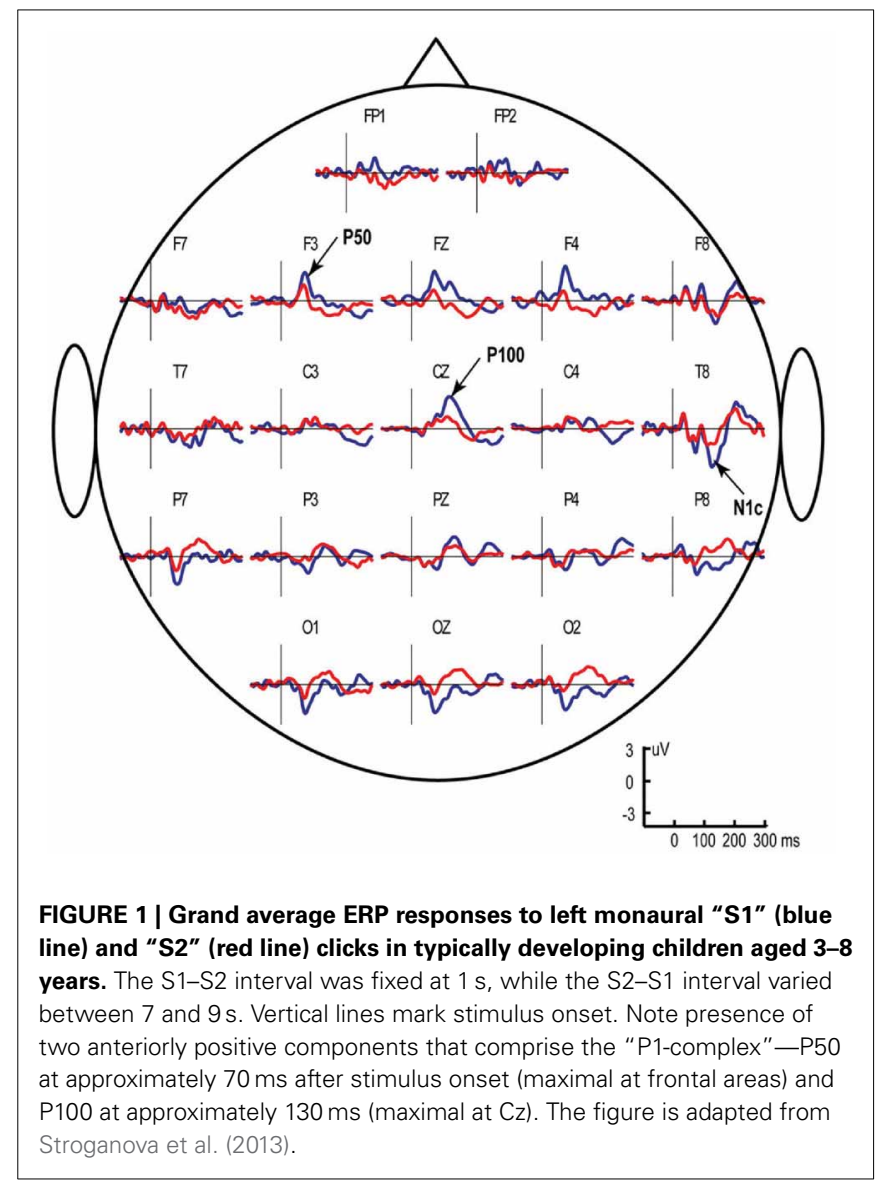

the main focus of interest, one should avoid directing subject's attention toward the auditory stimuli.

All published "sensory gating" studies in children with ASD employed silent movies to keep children busy and calm during auditory stimuli presentation. The stimuli were thus presented beyond the focus of child's attention. In case of the auditory P50, both S1 amplitude and S2/S1 ratio appear to be normal in nonretarded children with ASD (Kemner et al., 2002; Orekhova et al., 2008; Oranje et al., 2013). The decreased P50 S2/S1 ratio has been found only in those children with ASD who were mentally retarded (Orekhova et al., 2008). Even the retarded children, however, had normal P50 S1 amplitude. The only available adult study that applied "sound counting" modification of the paradigm has also reported normal S1 P50 amplitude and sensory gating in ASD participants (Magnee et al., 2009). These P50 findings sharply differentiate between individuals with ASD and those with schizophrenia who typically demonstrate P50 abnormalities, such as elevated S2/S1 ratio and decreased P50/S1 response (Chang et al., 2011).

Using a modification of the auditory sensory gating paradigm, Orekhova et al. (2012) have shown that despite having a normal P50, the 8- to 15-year-old children with ASD lacked normal rightward lateralization of the magnetic $\mathrm{P} 100 \mathrm{~m}$ response to binaural clicks. This abnormal lateralization was mainly due to the righthemispheric $\mathrm{P} 100 \mathrm{~m}$ reduction in ASD and correlated with the 


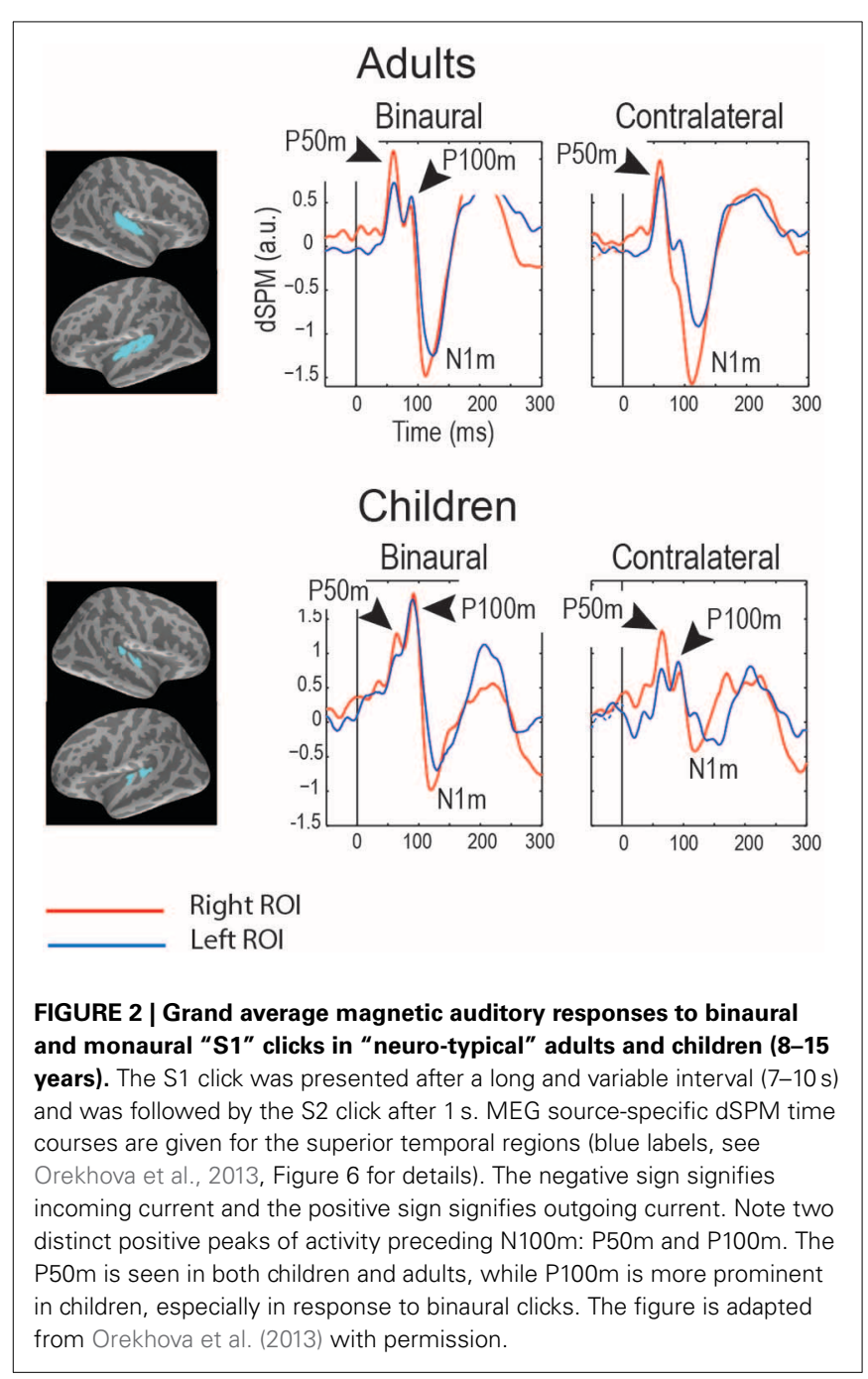

presence of sensory modulation difficulties in auditory domain. A later EEG study applying a similar paradigm but using monaural clicks in younger (4- to 8-year-old) participants with ASD revealed reduction of the P100 S1 amplitude and P100 S2/S1 amplitude ratio to the left click "addressed" to the right hemisphere, but a fairly normal responses to the right clicks addresses to the left hemisphere. The reduced contralateral (right hemispheric) P100 response to the left click and the reduced rightward P100 lateralization in children with ASD correlated both with the presence of auditory modulation difficulties and with developmental delay. The right-hemispheric reduction of the auditory response to temporally novel (S1) binaural clicks in 4- to 8-yearold children with autism has been also found for a somewhat later (approximately $140 \mathrm{~ms}$ ) obligatory ERP component N1c (Orekhova et al., 2009). Notably, similarly to P100, N1c to temporally novel stimuli was lateralized to the right hemisphere in the typically developing children, but not in those with ASD.

Collectively, these "sensory gating" studies consistently show that the processing of potentially salient but unattended and poorly predictable (presented with long and variable intervals) auditory stimuli is impaired in children with ASD. This impairment manifests itself in dampened reactivity of the right hemisphere at around $100 \mathrm{~ms}$ after stimulus onset and reflects the reduced bottom-up non-specific modulation of cortical auditory areas by reticular ascending arousal pathways. This righthemispheric deficit in pre-attentive arousal may reflect the same neural deficit that underlies occasional behavioral unresponsiveness to auditory stimuli and even to stimuli of other sensory modalities in individuals with ASD and may contribute to their attention re-orienting difficulties.

The lateralized deficit in early pre-attentive arousal may result in a failure to activate the normally rightward-lateralized ventral attention network subserving attention re-orienting (Corbetta et al., 2008). This hypothesis predicts the presence of lateralized abnormalities in attention re-orienting behavior in people with ASD.

\section{LATERALIZED ABNORMALITIES IN ATTENTION RE-ORIENTING IN ASD}

The brain network responsible for vigilance and attention re-orienting is strongly lateralized to the right hemisphere. Therefore, the unilateral damage to the right hemisphere, as compared to the unilateral damage to the left hemisphere, results much more frequently in decreased attentiveness to the contra-lateral left hemi-space (hemi-spatial neglect) and generally decreased arousal level (Mesulam, 1981; Robinson, 1985; Corbetta and Shulman, 2011).

Notably, left-sided unilateral neglect in patients with right brain damage is causally linked to both decreased arousal and its electrophysiological index - an auditory P1 response to binaural S1 clicks in the S1-S2 paradigm (Woods et al., 2012). Two available ERP studies in neglect patients that used monaural auditory stimuli showed reduction of the "obligatory" ERP responses to the left-sided as compared to the right-sided auditory stimulation (Deouell et al., 2000; Tarkka et al., 2011). This asymmetrical response attenuation in neglect patients resembles our finding in children with ASD suggesting similar neural deficiencies in the two clinical populations. Hence, it is likely that the righthemispheric arousal deficit found in children with ASD may also lead to the left-sided attention deficit similar to that in neglect patients.

Two decades ago Bryson and Wainwright-Sharp hypothesized that attentional abnormalities in people with autism may represent a "developmental neglect syndrome" (Bryson et al., 1990). In line with this hypothesis Casey and colleagues have found that autistic savants had a particular difficulty with disengaging and shifting attention to the left hemispace (Casey et al., 1993). Although disengagement deficit in ASD individuals has been subsequently replicated in many studies across their life span (see Ames and Fletcher-Watson, 2010 for review), its dependence on the visual hemi-field was either not studied or was shown to be bilateral (Townsend et al., 1996).

It would appear that the above findings are at odds with our prediction that attention re-orienting difficulties in ASD are skewed to the left hemispace. However, even in patients with brain lesions and a sub-clinical form of the left-sided unilateral neglect, the left-sided extinction is evident only during high attention load at a fixation point (Bonato, 2012). Hence, such 
left-sided predominance of the attention disengagement deficit in individuals with ASD is likely to be subtle and may therefore critically depend on preceding engagement. Consequently, specific attributes of the experimental task applied to uncover symptoms of behavioral neglect in ASD may be of particular importance. It is interesting in this respect that, while performing a demanding spatial working memory task, the 3- to 5-year-old children with ASD experienced significantly greater difficulties when required to re-orient attention to the left rather than to the right from the previously attended location (Tsetlin et al., 2008). This right-sided bias was not observed in the typically developing age-matched control children. The other example of atypical attention lateralization in children with ASD comes from the face processing studies. While presented with a face, typically developing infants and children tend to make the first saccade to the left, while this normal left gaze bias is absent in young children with ASD (Guillon et al., 2013). Although absence of the left gaze bias may reflect face processing atypicalities in ASD, it is also generally in line with atypical lateralization of attention.

Kawakubo et al. (2007) provided the first electrophysiological evidence for dysfunction of the brain attentional disengagement system in autism. They found abnormal pre-saccadic potential in adults with autism during performance of a "gap-overlap" task requiring gaze shifts to peripheral targets. The atypically high presaccadic positivity in subjects with autism was found only under the "overlap" condition and has been assumed by the authors to reflect the allocation of extra effort for attentional disengagement. Interestingly, the authors reported a significant ANOVA Side $\times$ Condition interaction effect, which is illustrated in their Figure 3. Their results show that enhanced pre-saccadic positivity in subjects with autism preceded only left peripheral visual targets. This finding suggests that subjects with autism allocated more resources to divert their gaze to the left then to the right peripheral stimuli.

Apart from experiencing difficulties with orienting to the left hemispace, the neglect patients with right brain damage demonstrate abnormally speeded saccades to the right visual field (Natale et al., 2007). This rightward bias is thought to result from hyperexcitability of intact left hemispheric cortex due to its reduced inhibition by the damaged right hemisphere (Koch et al., 2008, 2013). Interestingly, abnormally speeded saccades to the right have been reported also in adults with autism (D'Cruz et al., 2009), thus indirectly supporting the hypothesis about the right-hemispheric deficit.

Collectively, the results of the above-summarized studies suggest some similarity between individuals with ASD and neglect patients with the right-hemispheric damage. Although to a different degree, both groups experience attention orienting bias and/or relatively greater difficulty in re-orienting to the left space, which is more evident when attention is strongly engaged into a previously attended spatial location. We would like to stress that the suggested role of the right-lateralized dysfunction in attention re-orienting problems in ASD does not mean that ASD is the "right-hemispheric disorder." Indeed, structural abnormalities of gray and white matter in ASD are observed in both hemispheres (e.g., Travers et al., 2012; Greimel et al., 2013). An atypical pattern of structural cortical lateralization in children with ASD (Herbert et al., 2005) also implies an atypical development of both hemispheres rather than a specific unilateral deficit. The abnormal lateralization of language function to the right hemisphere was frequently reported in ASD and correlated with more severe language impairment (Eyler et al., 2012; Lindell and Hudry, 2013). Thus, there is convincing evidence that autism is associated with atypical brain lateralization and specialization as well as abnormal functioning of both hemispheres. Nevertheless, taking into account normally rightward lateralization of attention re-orienting function in the brain, the right-hemispheric dysfunction seems to be of particular relevance for attention problems in ASD.

Unlike neglect patients with brain lesions, the lateralized bias in ASD is likely to be explained by more subtle dysfunctions that particularly adversely affect the right-hemispheric attention networks. The abnormal cholinergic arousal may be one such mechanisms contributing to both lateralized ERP abnormality and attention re-orienting difficulties in ASD.

\section{CHOLINERGIC ABNORMALITIES IN ASD: POSSIBLE EFFECTS ON ERP/ERFs AND BEHAVIOR}

Cholinergic neuro-modulatory system is critically involved in regulation of attention re-orienting and arousal (Everitt and Robbins, 1997; Sarter and Bruno, 2000; Sarter et al., 2005). Therefore, there is a good reason to believe that the cholinergic abnormalities found in individuals with autism (Deutsch et al., 2010; Anand et al., 2011) contribute to their attention and arousal regulation problems.

There are two major groups of cholinergic neurons. The first group is located in the basal forebrain and is often referred to as the magnocellular basal forebrain cholinergic system (Mesulam et al., 1983a,b; Mesulam, 1995). Nucleus basalis of Meynert is a major nucleus of the basal forebrain that projects to cerebral cortex and amygdala, while vertical limb nucleus of the diagonal band of Broca is an important cholinergic nucleus that innervates hippocampus. The second group is located in the brainstem in the region of the pedunculopontine tegmental nucleus (PPTg) and laterodorsal pontine tegmentum. Brainstem cholinergic neurons principally innervate the thalamus.

Cholinergic projection aids the processing of stimuli at a cortical level by enhancing the impact of salient information via a mechanism, which produces increases in signal to noise ratio (Robbins, 1997). The arousal-induced attentional processing (i.e., stimulus detection, selection and processing as a result of a novel, highly salient, aversive, or incentive stimuli) is mediated via the ability of bottom-up brainstem ascending noradrenergic projections to the basal forebrain to activate or "recruit" basal forebrain-telencephalic circuits (Sarter and Bruno, 2000). Thus, integrity of cholinergic projections of basal forebrain and their interaction with noradrenergic arousal is essential for efficient orienting of attention to novel and salient stimulation.

Remarkably, morphological abnormalities of basal forebrain were reported in children with autism. Riva et al. (2011) observed gray matter reduction in the basal forebrain of young children with ASD. The uncinate fasciculus (UF) is the major rightlateralized (Highley et al., 2002) fiber tract that connects inferior frontal and anterior temporal lobes and amygdale and carries 
cholinergic fibers from nucleus basalis of Meynert to these structures. Cheon et al. (2011) have found reduced fractional anisotropy and increased radial diffusivity in UF in boys with autism. This finding suggests reduced cholinergic modulation of fronto-temporal areas and amygdala. Neurons of another cholinergic branch located in diagonal band of Broca are also affected in ASD (Bauman and Kemper, 2005). Bauman and Kemper (2005) have shown that neurons of this nucleus were unusually large in the brains of children with autism younger than 13 years, whereas in brains of adult persons with autism (age 21 years and older) neurons were small, pale and decreased in number.

An interesting support for cholinergic system dysfunction in ASD comes from a recent study by Lemonnier et al. (2013). The authors have shown that children with ASD had significantly higher rate of "red dermographism"-a skin reaction involving the cholinergic system-than children exhibiting typical development. Yet another support comes from a sleep study that has found strongly reduced percentage of REM sleep in children with ASD compared with either typically developing or mentally retarded children without autism (Buckley et al., 2010). As acetylcholine is the main driver of REM sleep, Buckley et al. (2010) suggested that reduced REM/slow sleep ratio in autism may reflect a cholinergic dysfunction.

In the brain, acetylcholine acts through two major types of receptors-muscarinic and nicotinic. Reduced expression of cholinergic receptors has been reported in post-mortem brain tissues of people with autism (Perry et al., 2001; Martin-Ruiz et al., 2004; Ray et al., 2005) and was especially strong for $\alpha 4$ and $\beta 2$ nicotinic acetylcholine receptor ( $\mathrm{nAChR}$ ) subunits in the "nonspecific" thalamic nuclei (Anand et al., 2011). Interestingly, strongly reduced concentration of the $\alpha 4 \beta 2-n A C h R$ was found in persons with ASD in Brodman area 39, which overlaps TPJthe cortical area principally involved in attention re-orienting (Martin-Ruiz et al., 2004). The nAChR abnormalities in ASD are likely to be post-transcriptional (Anand et al., 2011). Indeed, significant reduction in expression of the $\mathrm{nAChR}$ subunits, but not their mRNA, has been observed in post-mortem brains in autism (Anand et al., 2011). Neurorexin-1 abnormalities, reported in some individuals with autism, may also contribute to the cholinergic dysfunction because they result in abnormal targeting of $\alpha 4 \beta 2-n A C h R$ to pre-synaptic terminals in neurons (Cheng et al., 2009).

Taking into account the convincing evidance about nAChRmediated cholinergic disturbances in individuals with ASD it has been proposed that agonists and partial agonists for nicotinic acetylcholine receptors and modulators that enhance efficiency of these receptors may be useful for pharmacological treatment of autism (Deutsch et al., 2010; Anand et al., 2011). Preliminary clinical trials have indeed shown positive results (Nicolson et al., 2006).

There is evidence that the nAChRs are of particular importance for regulation of attention disengagement and shifting in neuro-typical individuals (Witte et al., 1997; Greenwood et al., 2005, 2009, 2012), while muscarinic receptors may underly tonic aspects of vigilance (Greenwood et al., 2009). Normal genetic variations in $\alpha 4$ subunit of $\mathrm{nAChR}$ have an impact on individual's ability to re-orient (disengage) attention. Individuals carrying two " $\mathrm{T}$ " alleles of the nAChR- $\alpha 4$ gen ( $\mathrm{T} / \mathrm{T}$ homozygotes) had the greatest cost of invalid relative to neutral cues in Posner's attention task, while $\mathrm{C} / \mathrm{C}$ homozigotes demonstrated the greatest benefit of a valid cue (Parasuraman et al., 2005). The C/C homozygotes also had a greater ability to adapt (scale) their attention focus (Greenwood et al., 2005). It has been shown that the presence of different $n A C h R-\alpha 4$ alleles affects brain activity during attention re-orienting, resulting in activation of different brain regions of the right temporo-parietal cortex (Giessing et al., 2012). These observations not only support involvement of $\mathrm{nAChR}-\alpha 4$ in attention re-orienting in neurotypical individuals, but also provide a link between nAChRs abnormalities and attention re-orienting difficulties in ASD. Specifically, the nAChR-mediated deficits found in individuals with ASD may lead to pre-attentive arousal abnormalities and altered ERP/ERF responses to novel or salient stimuli.

It has been long known that cholinergic arousal mechanisms are involved in generation of $\mathrm{P} 1$ (P50) response to clicks in human adults and in animals (Buchwald et al., 1991; Skinner et al., 2004). Many studies linked the decreased P50 sensory gating in patients with schizophrenia with a particular type of nAChR-nAChR- $\alpha 7$ (Adler et al., 1999; Leonard et al., 2002; Martin and Freedman, 2007; Ishikawa and Hashimoto, 2011). The presence of a normal P50 in high-functioning people with ASD suggests a lack of considerable functional deficit of the $\mathrm{nAChR}-\alpha 7$, at least in the brain circuits involved in P50 generation. The dampening of the later child-specific P100 component (Orekhova et al., 2012; Stroganova et al., 2013), on the other hand, could be potentially explained by functional deficit of another nAChR subtypes. One possible candidate is $\alpha 4 \beta 2-\mathrm{nAChR}$. Indeed, a post-mortem study has shown decreased expression of $\alpha 4$ and $\beta 2 \mathrm{nA} \mathrm{ChR}$ subunits, but a normal $\alpha 7$ expression in parietal cortical areas of individuals with ASD (Martin-Ruiz et al., 2004). Possible role of $\mathrm{nAChR}-\alpha 4 \beta 2$ in P100 generation is also indirectly supported by the animal studies. These studies have shown that modulation of $\alpha 4 \beta 2-n A C h R$ activation in mice does not influence the magnitude of hippocampal P20 - the human analog of P50 - but affects the amplitude of the component succeeding P20 (hippocampal N40) (Rudnick et al., 2009; Featherstone et al., 2012).

There is convincing evidence in the literature that $\mathrm{nAChR}$ stimulation mainly affects the attention reorienting network of the right hemisphere. Witte and colleagues observed that, in both humans and Rhesus monkeys, nicotine improved disengagement mainly by reducing reaction times to the targets presented in the left visual field (Witte et al., 1997). The authors therefore concluded that nicotine speeds processing mainly in the right hemisphere. Vossel et al. (2010) investigated effect of nicotine on attention in neglect patients and have shown that the drug improved re-orienting only in those patients in whom the right parietal and temporal cortex was intact (without lesions) and only in the case of re-orienting to the left hemi-space. The evidence for a possible asymmetrical effect of nicotine on obligatory ERP components comes from the study of Impey et al. (2013). They have found that acute nicotine administration increases the amplitude of visual P1 response to peripheral targets specifically in the right hemisphere of healthy individuals. Using fMRI, Thiel and Fink (2007) have found that during attention to visual and auditory 
stimuli nicotine modulated activity in multiple cortical regions, but that the only commonly affected area for the two modalities was the right superior temporal gyrus (right TPJ) - the crucial part of the ventral attention network.

To summarize, the nAChR-mediated arousal is critically involved in attention disengagement to peripheral targets and has a "left hemispace bias." If stimulation of nicotinic receptors by nicotine primarily affects re-orienting primarily through activation of the right hemisphere, then putative nicotinic cholinergic dysfunction in ASD should reduce the right hemispheric response to the novel or salient unattended stimuli. In this way, nicotinic cholinergic dysfunction could explain reviewed findings on both right hemispheric preponderance in P100 abnormalities and left-sided bias in attention disengagement difficulties in ASD.

\section{CONCLUSIONS}

Detection of new events occurring outside the focus of attention is fundamental to adaptive functioning and is most critical when attention is focused elsewhere. The unattended novel sensory events may demand further analysis according to their task relevance and may appear important for survival. Behavioral and physiological findings reviewed in this article imply that brains of many people with autism are, to a certain extent, impenetrable to such unattended but potentially salient changes in the immediate sensory environment. This deficit may lead to a spectrum of unusual behaviors that are typically observed in individuals with ASD and, being considered from different perspectives, appear as arousal regulation problems, attention re-orienting difficulties or abnormal modulation of the behavioral response to sensory events. Here we reviewed studies that applied ERP/ERF to investigate neural processing of salient (rare, novel, or deviant) auditory stimuli in ASD. We put forward a hypothesis that atypical processing of deviance and novelty in individuals with ASD may be grounded in the failure of nicotinic cholinergic arousal pathways to engage cortical mechanisms involved in detection of changes in the environment and appraisal of their novelty, if these changes occur beyond the currently attended sensory stream.

We hypothesize that in children with ASD the nicotinic cholinergic deficit, well documented in these disorders, manifests itself in reduction and abnormal lateralization of the child-specific P100 ERP/ERF response to temporally novel acoustic events. The other stages of the brain response to a novel event-automatic detection of physical changes in auditory stream indexed by MMN and evaluation of stimulus novelty indexed by the P3a componentare strongly modulated in people with ASD by direction of their attention. Abnormal reduction of these components occurs only when the stimuli are presented beyond the attended auditory stream. This may reflect a failure of the earlier "cholinergicarousal" processes to initiate attention re-orienting. The reduced cholinergic arousal thus appears to be a core neuro-functional deficit underlying slow and inefficient attention re-orienting in individuals with ASD throughout the life span.

The suggested link between the P100 abnormalities, the reduced nicotinic receptor-mediated activity, and the slow attention re-orienting in children with ASD allows formulating a few testable predictions for future research. First, it predicts that the child P100 component would be modulated by genetic variations of nAChR subunits in both typically developing children and in those with ASD. Second, taking into account the well-documented role of the nAChR-mediated arousal in attention re-orienting to the left hemispace, it predicts correlation between the right hemispheric P100 abnormalities and the lateralized attention re-orienting difficulties in ASD. We anticipate that in case of high attention load this re-orienting deficit should be more pronounced for left-sided stimuli. Third, the reduced nicotinic receptor-mediated activity may be present early in life and influence both P100 and attention re-orienting behavior in those infants "at risk" who would be later diagnosed with ASD. Further studies linking ERP/ERF findings with attention behavior and those searching for their neurochemical and genetic bases will help to understand causes of attention problems and sensory modulation difficulties in children with ASD and may prove helpful to direct early intervention.

\section{AUTHOR CONTRIBUTIONS}

The authors contributed equally to the work, such as the conception and design of the paper, review of the literature, work drafting, and final approval of the version to be published. The authors agreed on all aspects of the work in ensuring that questions related to the accuracy and integrity of the work are appropriately investigated and resolved.

\section{ACKNOWLEDGMENTS}

This research was supported by grant \# 16.518.11.7088 from the Russian Ministry of Science and Education and grant ofi-m \# 0906-12042 from Russian foundation for basic research.

\section{REFERENCES}

Adler, L. E., Freedman, R., Ross, R. G., Olincy, A., and Waldo, M. C. (1999). Elementary phenotypes in the neurobiological and genetic study of schizophrenia. Biol. Psychiatr. 46, 8-18. doi: 10.1016/S0006-3223(99)00085-2

Albuquerque, E. X., Pereira, E. F., Alkondon, M., and Rogers, S. W. (2009). Mammalian nicotinic acetylcholine receptors: from structure to function. Physiol. Rev. 89, 73-120. doi: 10.1152/physrev.00015.2008

Allen, G., and Courchesne, E. (2001). Attention function and dysfunction in autism. Front. Biosci. 6, D105-D119. doi: 10.2741/allen

Ames, C., and Fletcher-Watson, S. (2010). A review of methods in the study of attention in autism. Dev. Rev. 30, 52-73. doi: 10.1016/j.dr.2009.12.003

Anand, R., Amici, S. A., Ponath, G., Robson, J. I., Nasir, M., and McKay, S. B. (2011). "Nicotinic acetylcholine receptor alterations in autism spectrum disorders - biomarkers and therapeutic targets," in Autism - A Neurodevelopmental Journey from Genes to Behaviour, ed V. Eapen (InTech), 123-146. doi: 10.5772/ 20752

Andersson, S., Posserud, M. B., and Lundervold, A. J. (2013). Early and late auditory event-related potentials in cognitively high functioning male adolescents with autism spectrum disorder. Res. Autism Spect. Disabil. 7, 815-823. doi: 10.1016/j.rasd.2013.03.007

Atienza, M., Cantero, J. L., and Gomez, C. M. (2001). The initial orienting response during human REM sleep as revealed by the N1 component of auditory event-related potentials. Int. J. Psychophysiol. 41, 131-141. doi: 10.1016/S01678760(00)00196-3

Bahrick, L. E., and Todd, J. T. (2013). "Relations among speed of attention shifting, background noise, and symptom severity in children with autism spectrum disorders," in IMFAR 2013 (San Sebastián).

Baranek, G. T., David, F. J., Poe, M. D., Stone, W. L., and Watson, L. R. (2006). Sensory experiences questionnaire: discriminating sensory features in young children with autism, developmental delays, and typical development. J. Child Psychol. Psychiatry. 47, 591-601. doi: 10.1111/j.1469-7610.2005. 01546.x 
Baranek, G. T., Watson, L. R., Boyd, B. A., Poe, M. D., David, F. J., and McGuire, L. (2013). Hyporesponsiveness to social and nonsocial sensory stimuli in children with autism, children with developmental delays, and typically developing children. Dev. Psychopathol. 25, 307-320. doi: 10.1017/S0954579412001071

Baron-Cohen, S., Leslie, A. M., and Frith, U. (1985). Does the autistic child have a theory of mind. Cognition 21, 37-46. doi: 10.1016/0010-0277(85)90022-8

Bauman, M. L., and Kemper, T. L. (2005). Neuroanatomic observations of the brain in autism: a review and future directions. Int. J. Dev. Neurosci. 23, 183-187. doi: 10.1016/j.ijdevneu.2004.09.006

Ben-Sasson, A., Cermak, S. A., Orsmond, G. I., Tager-Flusberg, H., Kadlec, M. B., and Carter, A. S. (2008). Sensory clusters of toddlers with autism spectrum disorders: differences in affective symptoms. J. Child Psychol. Psyc. 49, 817-825. doi: 10.1111/j.1469-7610.2008.01899.x

Berntson, G. G., Shafi, R., Knox, D., and Sarter, M. (2003). Blockade of epinephrine priming of the cerebral auditory evoked response by cortical cholinergic deafferentation. Neuroscience 116, 179-186. doi: 10.1016/S0306-4522(02)00702-9

Bonato, M. (2012). Neglect and extinction depend greatly on task demands: a review. Front. Hum. Neurosci. 6:195. doi: 10.3389/fnhum.2012.00195

Bonneh, Y. S., Belmonte, M. K., Pei, F., Iversen, P. E., Kenet, T., Akshoomoff, N., et al. (2008). Cross-modal extinction in a boy with severely autistic behaviour and high verbal intelligence. Cogn. Neuropsychol. 25, 635-652. doi: 10.1080/02643290802106415

Bonnel, A., Mottron, L., Peretz, I., Trudel, M., Gallun, E., and Bonnel, A. M. (2003). Enhanced pitch sensitivity in individuals with autism: a signal detection analysis. J. Cogn. Neurosci. 15, 226-235. doi: 10.1162/089892903321208169

Boutros, N. N., and Belger, A. (1999). Midlatency evoked potentials attenuation and augmentation reflect different aspects of sensory gating. Biol. Psychiatry 45, 917-922. doi: 10.1016/S0006-3223(98)00253-4

Brenner, C. A., Kieffaber, P. D., Clementz, B. A., Johannesen, J. K., Shekhar, A., O'Donnell, B. F., et al. (2009). Event-related potential abnormalities in schizophrenia: a failure to "gate in" salient information? Schizophr. Res. 113, 332-338. doi: 10.1016/j.schres.2009.06.012

Bryson, S. E., Wainwright-Sharp, J. A., and Smith, I. M. (1990). Chapter 21 Autism: a developmental spatial neglect syndrome? in Advances in Psychology. Vol. 69, ed T. E. James (North-Holland: Elsevier Science Publishers B.V.), 405-427.

Bryson, S. E., Zwaigenbaum, L., Brian, J., Roberts, W., Szatmari, P., Rombough, V., et al. (2007). A prospective case series of high-risk infants who developed autism. J. Autism Dev. Disord. 37, 12-24. doi: 10.1007/s10803-006-0328-2

Buchwald, J. S., Erwin, R., Vanlancker, D., Guthrie, D., Schwafel, J., and Tanguay, P. (1992). Midlatency auditory evoked-responses - p1 abnormalities in adult autistic subjects. Electroencephalogr. Clin. Neurophysiol. 84, 164-171. doi: 10.1016/0168-5597(92)90021-3

Buchwald, J. S., Rubinstein, E. H., Schwafel, J., and Strandburg, R. J. (1991). Midlatency auditory evoked-responses - differential-effects of a cholinergic agonist and antagonist. Electroencephalogr. Clin. Neurophysiol. 80, 303-309. doi: 10.1016/0168-5597(91)90114-D

Buckley, A. W., Rodriguez, A. J., Jennison, K., Buckley, J., Thurm, A., Sato, S., et al. (2010). Rapid eye movement sleep percentage in children with autism compared with children with developmental delay and typical development. Arch. Pediatr. Adolesc. Med. 164, 1032-1037. doi: 10.1001/archpediatrics.2010.202

Canitano, R., and Scandurra, V. (2011). Psychopharmacology in autism: an update. Prog. Neuropsychopharmacol. Biol. Psychiatry. 35, 18-28. doi: 10.1016/j.pnpbp.2010.10.015

Cardy, J. E. O., Flagg, E. J., Roberts, W., and Roberts, T. P. L. (2005). Delayed mismatch field for speech and non-speech sounds in children with autism. Neuroreport 16, 521-525. doi: 10.1097/00001756-200504040-00021

Casey, B. J., Gordon, C. T., Mannheim, G. B., and Rumsey, J. M. (1993). Dysfunctional attention in autistic savants. J. Clin. Exp. Neuropsychol. 15, 933-946. doi: 10.1080/01688639308402609

Ceponiene, R., Lepisto, T., Shestakova, A., Vanhala, R., Alku, P., Naatanen, R., et al. (2003). Speech-sound-selective auditory impairment in children with autism: they can perceive but do not attend. Proc. Natl. Acad. Sci. U.S.A. 100, 5567-5572. doi: 10.1073/pnas.0835631100

Chang, W. P., Arfken, C. L., Sangal, M. P., and Boutros, N. N. (2011). Probing the relative contribution of the first and second responses to sensory gating indices: a meta-analysis. Psychophysiology 48, 980-992. doi: 10.1111/j.14698986.2010.01168.x

Cheng, S. B., Amici, S. A., Ren, X. Q., McKay, S. B., Treuil, M. W., Lindstrom, J. M., et al. (2009). Presynaptic targeting of alpha4beta 2 nicotinic acetylcholine receptors is regulated by neurexin-1beta. J. Biol. Chem. 284, 23251-23259. doi: 10.1074/jbc.M109.017384

Cheon, K. A., Kim, Y. S., Oh, S. H., Park, S. Y., Yoon, H. W., Herrington, J., et al. (2011). Involvement of the anterior thalamic radiation in boys with high functioning autism spectrum disorders: a diffusion tensor imaging study. Brain Res. 1417, 77-86. doi: 10.1016/j.brainres.2011.08.020

Cohen, D. J., Caparulo, B., and Shaywitz, B. (1976). Primary childhood aphasia and childhood autism: clinical, biological, and conceptual observations. J. Am. Acad. Child Psychiatry 15, 604-645. doi: 10.1097/00004583-197601540-00002

Cohen, I. L., Gardner, J. M., Karmel, B. Z., Phan, H. T. T., Kittler, P., Gomez, T. R., et al. (2013). Neonatal brainstem function and 4-month arousalmodulated attention are jointly associated with autism. Autism Res. 6, 11-22. doi: 10.1002/aur.1259

Combs, L. A., and Polich, J. (2006). P3a from auditory white noise stimuli. Clin. Neurophysiol. 117, 1106-1112. doi: 10.1016/j.clinph.2006.01.023

Corbetta, M., Patel, G., and Shulman, G. L. (2008). The reorienting system of the human brain: from environment to theory of mind. Neuron 58, 306-324. doi: 10.1016/j.neuron.2008.04.017

Corbetta, M., and Shulman, G. L. (2011). Spatial neglect and attention networks. Annu. Rev. Neurosci. 34, 569-599. doi: 10.1146/annurev-neuro-061010-113731

Courchesne, E., Kilman, B. A., Galambos, R., and Lincoln, A. J. (1984). Autism processing of novel auditory information assessed by event-related brain potentials. Electroencephalogr. Clin. Neurophysiol. 59, 238-248. doi: 10.1016/01685597(84)90063-7

Courchesne, E., Lincoln, A. J., Kilman, B. A., and Galambos, R. (1985). EventRelated brain potential correlates of the processing of novel visual and auditory information in autism. J. Autism Dev. Disord. 15, 55-76. doi: 10.1007/BF01837899

Crane, L., Goddard, L., and Pring, L. (2009). Sensory processing in adults with autism spectrum disorders. Autism 13, 215-228. doi: $10.1177 / 1362361309103794$

D’Cruz, A. M., Mosconi, M. W., Steele, S., Rubin, L. H., Luna, B., Minshew, N., et al. (2009). Lateralized response timing deficits in autism. Biol. Psychiatry 66, 393-397. doi: 10.1016/j.biopsych.2009.01.008

Dahlgren, S. O., and Gillberg, C. (1989). Symptoms in the first two years of life. A preliminary population study of infantile autism. Eur. Arch. Psychiatry Neurol. Sci. 238, 169-174. doi: 10.1007/BF00451006

Dawson, G., Meltzoff, A. N., Osterling, J., Rinaldi, J., and Brown, E. (1998). Children with autism fail to orient to naturally occurring social stimuli. J. Autism Dev. Disord. 28, 479-485. doi: 10.1023/A:1026043926488

de Lecea, L., Carter, M. E., and Adamantidis, A. (2012). Shining light on wakefulness and arousal. Biol. Psychiatry. 71, 1046-1052. doi: 10.1016/j.biopsych.2012.01.032

Deouell, L. Y. (2007). The frontal generator of the mismatch negativity revisited. J. Psychophysiol. 21, 188-203. doi: 10.1027/0269-8803.21.34.188

Deouell, L. Y., Bentin, S., and Soroker, N. (2000). Electrophysiological evidence for an early (pre-attentive) information processing deficit in patients with right hemisphere damage and unilateral neglect. Brain 123, 353-565. doi: 10.1093/brain/123.2.353

Deutsch, S. I., Urbano, M. R., Neumann, S. A., Burket, J. A., and Katz, E. (2010). Cholinergic abnormalities in autism: is there a rationale for selective nicotinic agonist interventions? Clin. Neuropharmacol. 33, 114-120. doi: 10.1097/WNF.0b013e3181d6f7ad

Dringenberg, H. C., and Vanderwolf, C. H. (1998). Involvement of direct and indirect pathways in electrocorticographic activation. Neurosci. Biobehav. Rev. 22, 243-257. doi: 10.1016/S0149-7634(97)00012-2

Dunn, M. A., Gomes, H., and Gravel, J. (2008). Mismatch negativity in children with autism and typical development. J. Autism Dev. Disord. 38, 52-71. doi: 10.1007/s10803-007-0359-3

Eggermont, J. J., and Ponton, C. W. (2003). Auditory-evoked potential studies of cortical maturation in normal hearing and implanted children: correlations with changes in structure and speech perception. Acta Oto-Laryngol. 123, 249-252. doi: 10.1080/0036554021000028098

Elison, J. T., Paterson, S. J., Wolff, J. J., Reznick, J. S., Sasson, N. J., Gu, H., et al. (2013). White matter microstructure and atypical visual orienting in 7-month-olds at risk for autism. Am. J. Psychiatry 170, 899-908. doi: 10.1176/appi.ajp.2012.12091150

Elsabbagh, M., Fernandes, J., Webb, S. J., Dawson, G., Charman, T., Johnson, M. H., et al. (2013). Disengagement of visual attention in infancy is associated with 
emerging autism in toddlerhood. Biol. Psychiatry 74, 189-194. doi: 10.1016/j. biopsych.2012.11.030

Everitt, B. J., and Robbins, T. W. (1997). Central cholinergic systems and cognition. Annu. Rev. Psychol. 48, 649-684. doi: 10.1146/annurev.psych.48.1.649

Eyler, L. T., Pierce, K., and Courchesne, E. (2012). A failure of left temporal cortex to specialize for language is an early emerging and fundamental property of autism. Brain 135, 949-960. doi: 10.1093/brain/awr364

Fatemi, S. H., Folsom, T. D., Kneeland, R. E., Yousefi, M. K., Liesch, S. B., and Thuras, P. D. (2013). Impairment of fragile X mental retardation proteinmetabotropic glutamate receptor 5 signaling and its downstream cognates ras-related C3 botulinum toxin substrate 1, amyloid beta A4 precursor protein, striatal-enriched protein tyrosine phosphatase, and homer 1, in autism: a postmortem study in cerebellar vermis and superior frontal cortex. Mol. Autism 4, 21. doi: 10.1186/2040-2392-4-21

Featherstone, R. E., Phillips, J. M., Thieu, T., Ehrlichman, R. S., Halene, T. B., Leiser, S. C., et al. (2012). Nicotine receptor subtype-specific effects on auditory evoked oscillations and potentials. PLoS ONE 7:7. doi: 10.1371/journal.pone.0039775

Ferri, R., Elia, M., Agarwal, N., Lanuzza, B., Musumeci, S. A., and Pennisi, G. (2003). The mismatch negativity and the P3a components of the auditory eventrelated potentials in autistic low-functioning subjects. Clin. Neurophysiol. 114, 1671-1680. doi: 10.1016/S1388-2457(03)00153-6

Friedman, D., Cycowicz, Y. M., and Gaeta, H. (2001). The novelty P3: an eventrelated brain potential (ERP) sign of the brain's evaluation of novelty. Neurosci. Biobehav. Res. 25, 355-373. doi: 10.1016/S0149-7634(01)00019-7

Frith, U., and Happe, F. (1994). Autism - beyond theory of mind. Cognition 50, 115-132. doi: 10.1016/0010-0277(94)90024-8

Giessing, C., Neber, T., and Thiel, C. M. (2012). Genetic variation in nicotinic receptors affects brain networks involved in reorienting attention. Neuroimage 59, 831-839. doi: 10.1016/j.neuroimage.2011.07.061

Giini, K., Burroughs, S., and Boutros, N. N. (2011). Relevance of attention in auditory sensory gating paradigms in schizophrenia a pilot study. J. Psychophysiol. 25, 60-66. doi: 10.1027/0269-8803/a000042

Gomes, H., Molholm, S., Ritter, W., Kurtzberg, D., Cowan, N., and Vaughan, H. G. (2000). Mismatch negativity in children and adults, and effects of an attended task. Psychophysiology 37, 807-816. doi: 10.1111/1469-8986.3760807

Gomot, M., Belmonte, M. K., Bullmore, E. T., Bernard, F. A., and Baron-Cohen, S. (2008). Brain hyper-reactivity to auditory novel targets in children with highfunctioning autism. Brain 131, 2479-2488. doi: 10.1093/brain/awn172

Gomot, M., Bernard, F. A., Davis, M. H., Belmonte, M. K., Ashwin, C., Bullmore, E. T., et al. (2006). Change detection in children with autism: an auditory event-related fMRI study. Neuroimage.29, 475-484. doi: 10.1016/j.neuroimage.2005.07.027

Gomot, M., Blanc, R., Clery, H., Roux, S., Barthelemy, C., and Bruneau, N. (2011). Candidate electrophysiological endophenotypes of hyper-reactivity to change in autism. J. Autism Dev. Disord. 41, 705-714. doi: 10.1007/s10803-010-1091-y

Gomot, M., Giard, M. H., Adrien, J. L., Barthelemy, C., and Bruneau, N. (2002). Hypersensitivity to acoustic change in children with autism: electrophysiological evidence of left frontal cortex dysfunctioning. Psychophysiology 39, 577-584. doi: 10.1111/1469-8986.3950577

Grandin, T., and Scariano, M. (1996). Emergence: Labeled Autistic. New York, NY: Warner Books.

Greenwood, P. M., Fossella, J. A., and Parasuraman, R. (2005). Specificity of the effect of a nicotinic receptor polymorphism on individual differences in visuospatial attention. J. Cogn. Neurosci. 17, 1611-1620. doi: 10.1162/089892905774597281

Greenwood, P. M., Lin, M. K., Sundararajan, R., Fryxell, K. J., and Parasuraman, R. (2009). Synergistic effects of genetic variation in nicotinic and muscarinic receptors on visual attention but not working memory. Proc. Natl. Acad. Sci. U.S.A. 106, 3633-3638. doi: 10.1073/pnas.0807891106

Greenwood, P. M., Parasuraman, R., and Espeseth, T. (2012). A cognitive phenotype for a polymorphism in the nicotinic receptor gene CHRNA4. Neurosci. Biobehav. Res. 36, 1331-1341. doi: 10.1016/j.neubiorev.2012.02.010

Greimel, E., Nehrkorn, B., Schulte-Ruther, M., Fink, G. R., Nickl-Jockschat, T., Herpertz-Dahlmann, B., et al. (2013). Changes in grey matter development in autism spectrum disorder. Brain Struct. Funct. 218, 929-942. doi: 10.1007/s00429-012-0439-9

Guillon, Q., Baduel, S., Hadjikhani, N., and Roge, B. (2013). "Looking to the left or looking to the right? Revisiting visual scanning of faces in young children with ASD,” in IMFAR 2-4 May (San Sebastián).
Hadlington, L., Bridges, A. M., and Darby, R. J. (2004). Auditory location in the irrelevant sound effect: the effects of presenting auditory stimuli to either the left ear, right ear or both ears. Brain Cogn. 55, 545-557. doi: 10.1016/j.bandc.2004.04.001

Harrington, R. A., Lee, L. C., Crum, R. M., Zimmerman, A. W., and HertzPicciotto, I. (2013). Serotonin hypothesis of autism: implications for selective serotonin reuptake inhibitor use during pregnancy. Autism Res. 6, 149-168. doi: 10.1002/aur.1288

Harris, N. S., Courchesne, E., Townsend, J., Carper, R. A., and Lord, C. (1999). Neuroanatomic contributions to slowed orienting of attention in children with autism. Brain Res. Cogn. Brain Res. 8, 61-71. doi: 10.1016/S0926-6410(99) 00006-3

Harrison, J., and Hare, D. J. (2004). Brief report: assessment of sensory abnormalities in people with autistic spectrum disorders. J. Autism Dev. Disord. 34, 727-730. doi: 10.1007/s10803-004-5293-z

Herbert, M. R., Ziegler, D. A., Deutsch, C. K., O’Brien, L. M., Kennedy, D. N., Filipek, P. A., et al. (2005). Brain asymmetries in autism and developmental language disorder: a nested whole-brain analysis. Brain.128, 213-226. doi: 10.1093/brain/awh330

Hermelin, B., and O'Connor, N. (1970). Psychological experiments with autistic children. 1st Edn. Oxford; New York: Pergamon Press.

Highley, J. R., Walker, M. A., Esiri, M. M., Crow, T. J., and Harrison, P. J. (2002). Asymmetry of the uncinate fasciculus: a post-mortem study of normal subjects and patients with schizophrenia. Cereb. Cortex 12, 1218-1224. doi: $10.1093 /$ cercor/12.11.1218

Hirstein, W., Iversen, P., and Ramachandran, V. S. (2001). Autonomic responses of autistic children to people and objects. Proc. R. Soc. B Biol. Sci. 268, 1883-1888. doi: 10.1098/rspb.2001.1724

Howard, M. A., Volkov, I. O., Mirsky, R., Garell, P. C., Noh, M. D., Granner, M., et al. (2000). Auditory cortex on the human posterior superior temporal gyrus. J. Comp. Neurol. 416, 79-92. doi: 10.1002/(SICI)10969861(20000103)416:1<79::AID-CNE6>3.0.CO;2-2

Howard, M. F., and Poeppel, D. (2009). Hemispheric asymmetry in mid and long latency neuromagnetic responses to single clicks. Hear. Res. 257, 41-52. doi: 10.1016/j.heares.2009.07.010

Hutt, C., Hutt, S. J., Lee, D., and Ounsted, C. (1964). Arousal and childhood autism. Nature 204, 908-909. doi: 10.1038/204908a0

Hutt, S. J., Hutt, C., Lee, D., and Ounsted, C. (1965). A behavioural and electroencephalographic study of autistic children. J. Psychiatr. Res. 3, 181-197. doi: 10.1016/0022-3956(65)90028-2

Ibanez, A. M., Martin, R. S., Hurtado, E., and Lopez, V. (2009). ERPs studies of cognitive processing during sleep. Int. J. Psychol. 44, 290-304. doi: 10.1080/00207590802194234

Impey, D., Chique-Alfonzo, M., Shah, D., Fisher, D. J., and Knott, V. J. (2013). Effects of nicotine on visuospatial attentional orienting in non-smokers. Pharmacol. Biochem. Behav. 106, 1-7. doi: 10.1016/j.pbb.2013.02.015

Ishikawa, M., and Hashimoto, K. (2011). alpha 7 Nicotinic acetylcholine receptor as a potential therapeutic target for schizophrenia. Curr. Pharm. Des. 17, 121-129. doi: 10.2174/138161211795049561

Jaaskelainen, I. P., Ahveninen, J., Bonmassar, G., Dale, A. M., Ilmoniemi, R. J., Levanen, S., et al. (2004). Human posterior auditory cortex gates novel sounds to consciousness. Proc. Natl. Acad. Sci. U.S.A. 101, 6809-6814. doi: 10.1073/pnas.0303760101

Jansson-Verkasalo, E., Ceponiene, R., Kielinen, M., Suominen, K., Jantti, V., Linna, S. L., et al. (2003). Deficient auditory processing in children with Asperger Syndrome, as indexed by event-related potentials. Neurosci. Lett. 338, 197-200. doi: 10.1016/S0304-3940(02)01405-2

Kanner, L. (1968). Autistic disturbances of affective contact. Acta Paedopsychiatr. $35,100-136$.

Karmel, B. Z., Gardner, J. M., Swensen, L., Cohen, I. L., London, E., Flory, M. J., et al. (2010). Early medical and behavioral characteristics of nicu infants later classified with ASD. Pediatrics 126, 457-467. doi: 10.1542/peds. 2009-2680

Kawakubo, Y., Kasai, K., Okazaki, S., Hosokawa-Kakurai, M., Watanabe, K., Kuwabara, H., et al. (2007). Electrophysiological abnormalities of spatial attention in adults with autism during the gap overlap task. Clin. Neurophysiol. 118, 1464-1471. doi: 10.1016/j.clinph.2007.04.015

Kawakubo, Y., Maekawa, H., Itoh, K., Hashimoto, O., and Iwanami, A. (2004). Spatial attention in individuals with pervasive developmental disorders using 
the gap overlap task. Psychiatry Res. 125, 269-275. doi: 10.1016/j.psychres.2003. 12.012

Keehn, B., Lincoln, A. J., Muller, R. A., and Townsend, J. (2010). Attentional networks in children and adolescents with autism spectrum disorder. J. Child Psychol. Psychiatry 51, 1251-1259. doi: 10.1111/j.1469-7610.2010.02257.x

Keehn, B., Muller, R. A., and Townsend, J. (2013). Atypical attentional networks and the emergence of autism. Neurosci. Biobehav. Res. 37, 164-183. doi: 10.1016/j.neubiorev.2012.11.014

Kemner, C., Oranje, B., Verbaten, M. N., and van Engeland, H. (2002). Normal P50 gating in children with autism. J. Clin. Psychiatry 63, 214-217. doi: 10.4088/JCP.v63n0307

Kemner, C., Verbaten, M. N., Cuperus, J. M., Camfferman, G., and van Engeland, H. (1995). auditory event-related brain potentials in autistic-children and 3 different control-groups. Biol. Psychiatry 38, 150-165. doi: 10.1016/00063223(94)00247-Z

Kinsbourne, M. (1987). “Cerebral-Brainstem relations in infantile autism," in Neurobiological Issues in Autism, eds E. Schopler and G. B. Mesibov (New York, NY: Plenum Press), 107-125. doi: 10.1007/978-1-4899-1992-2_6

Kinsbourne, M. (1991). "Overfocusing: an apparent subtype of attention deficit hyperactivity disorder," in Pediatric neurology: behavior and cognition of the child with brain dysfunction Pediatric and adolescent medicine, eds N. Amir, I. Rapin, and D. Branski (Basel; New York: Karger), 186.

Kisley, M. A., Noecker, T. L., and Guinther, P. M. (2004). Comparison of sensory gating to mismatch negativity and self-reported perceptual phenomena in healthy adults. Psychophysiology 41, 604-612. doi: 10.1111/j.14698986.2004.00191.x

Koch, G., Oliveri, M., Cheeran, B., Ruge, D., Lo Gerfo, E., Salerno, S., et al. (2008). Hyperexcitability of parietal-motor functional connections in the intact left-hemisphere of patients with neglect. Brain 131, 3147-3155. doi: 10.1093/brain/awn273

Koch, G., Veniero, D., and Caltagirone, C. (2013). To the other side of the neglected brain: the hyperexcitability of the left intact hemisphere. Neuroscientist 19, 208-217. doi: 10.1177/1073858412447874

Korpilahti, P., Jansson-Verkasalo, E., Mattila, M. L., Kuusikko, S., Suominen, K., Rytky, S., et al. (2007). Processing of affective speech prosody is impaired in Asperger syndrome. J. Autism Dev. Disord. 37, 1539-1549. doi: 10.1007/s10803006-0271-2

Kral, A., and Eggermont, J. J. (2007). What's to lose and what's to learn: development under auditory deprivation, cochlear implants and limits of cortical plasticity. Brain Res. Rev. 56, 259-269. doi: 10.1016/j.brainresrev.2007.07.021

Kuhl, P. K., Coffey-Corina, S., Padden, D., and Dawson, G. (2005). Links between social and linguistic processing of speech in preschool children with autism: behavioral and electrophysiological measures. Dev. Sci. 8, F1-F12. doi: 10.1111/j.1467-7687.2004.00384.x

Kujala, T., Aho, E., Lepisto, T., Jansson-Verkasalo, E., Nieminen-von Wendt, T., von Wendt, L., et al. (2007). Atypical pattern of discriminating sound features in adults with Asperger syndrome as reflected by the mismatch negativity. Biol. Psychol. 75, 109-114. doi: 10.1016/j.biopsycho.2006.12.007

Kujala, T., Kuuluvainen, S., Saalasti, S., Jansson-Verkasalo, E., von Wendt, L., and Lepisto, T. (2010). Speech-feature discrimination in children with Asperger syndrome as determined with the multi-feature mismatch negativity paradigm. Clin. Neurophysiol. 121, 1410-1419. doi: 10.1016/j.clinph.2010. 03.017

Kujala, T., Lepisto, T., Nieminen-von Wendt, T., Naatanen, P., and Naatanen, R. (2005). Neurophysiological evidence for cortical discrimination impairment of prosody in Asperger syndrome. Neurosci. Lett. 383, 260-265. doi: 10.1016/j.neulet.2005.04.048

Lacey, J. J. (1967). "Somatic response patterning and stress: some revisions of activation theory," in Psychological Stress, Issues in Research; the Century Psychology Series, eds M. H. Appley and R. Trumbull (New York, NY: Appleton-CenturyCrofts), 471.

Landry, R., and Bryson, S. E. (2004). Impaired disengagement of attention in young children with autism. J. Child Psychol. Psychiatry 45, 1115-11122. doi: 10.1111/j.1469-7610.2004.00304.x

Leekam, S. R., Nieto, C., Libby, S. J., Wing, L., and Gould, J. (2007). Describing the sensory abnormalities of children and adults with autism. J. Autism Dev. Disord. 37, 894-910. doi: 10.1007/s10803-006-0218-7

Lemonnier, E., Grandgeorge, M., Jacobzone-Leveque, C., Bessaguet, C., Peudenier, S., and Misery, L. (2013). Red dermographism in autism spectrum disorders: a clinical sign of cholinergic dysfunction? Res. Autism Spect. Disabl. 7, 601-605. doi: 10.1016/j.rasd.2013.01.005

Leonard, S., Gault, J., Hopkins, J., Logel, J., Vianzon, R., Short, M., et al. (2002). Association of promoter variants in the alpha 7 nicotinic acetylcholine receptor subunit gene with an inhibitory deficit found in schizophrenia. Arch. Gen. Psychiatry 59, 1085-1096. doi: 10.1001/archpsyc.59. 12.1085

Lepisto, T., Kujala, T., Vanhala, R., Alku, P., Huotilainen, M., and Naatanen, R. (2005). The discrimination of and orienting to speech and nonspeech sounds in children with autism. Brain Res. 1066, 147-157. doi: 10.1016/j.brainres.2005.10.052

Lepisto, T., Silokallio, S., Nieminen-von Wendt, T., Alku, P., Naatanen, R., and Kujala, T. (2006). Auditory perception and attention as reflected by the brain event-related potentials in children with Asperger syndrome. Clin. Neurophysiol. 117, 2161-2171. doi: 10.1016/j.clinph.2006.06.709

Lepisto, T., Wendt, T. N. V., von Wendt, L., Naatanen, R., and Kujala, T. (2007) Auditory cortical change detection in adults with Asperger syndrome. Neurosci. Lett. 414, 136-140. doi: 10.1016/j.neulet.2006.12.009

Lincoln, A., Lai, Z., and Jones, W. (2002). Shifting attention and joint attention dissociation in Williams syndrome: implications for the cerebellum and social deficits in autism. Neurocase 8, 226-232. doi: 10.1093/neucas/8.3.226

Lindell, A. K., and Hudry, K. (2013). Atypicalities in cortical structure, handedness, and functional lateralization for language in autism spectrum disorders. Neuropsychol. Rev. 23, 257-270. doi: 10.1007/s11065-013-9234-5

Liss, M., Saulnier, C., Kinsbourne, D. F., and Kinsbourne, M. (2006). Sensory and attention abnormalities in autistic spectrum disorders. Autism. 10, 155-172. doi: $10.1177 / 1362361306062021$

Lucker, J. R. (2013). Auditory hypersensitivity in children with autism spectrum disorders. Focus Autism Dev. Disabl. 28, 184-191. doi: $10.1177 / 1088357613475810$

Magnee, M., Oranje, B., van Engeland, H., Kahn, R. S., and Kemner, C. (2009). Cross-sensory gating in schizophrenia and autism spectrum disorder: EEG evidence for impaired brain connectivity? Neuropsychologia 47, 1728-1732. doi: 10.1016/j.neuropsychologia.2009.02.012

Mantini, D., Corbetta, M., Perrucci, M. G., Romani, G. L., and Del Gratta, C. (2009). Large-scale brain networks account for sustained and transient activity during target detection. Neuroimage 44, 265-274. doi: 10.1016/j.neuroimage.2008.08.019

Marshall, D. R. (2011). Impaired Visual Disengagement in Autism: Can this be Due to Stimulus Effects and Inherent Interest? Durham thesis, Durham University, Durham.

Martin, L. F., and Freedman, R. (2007). Schizophrenia and the alpha7 nicotinic acetylcholine receptor. Int. Rev. Neurobiol. 78, 225-246. doi: 10.1016/S00747742(06)78008-4

Martin-Ruiz, C. M., Lee, M., Perry, R. H., Baumann, M., Court, J. A., and Perry, E. K. (2004). Molecular analysis of nicotinic receptor expression in autism. Mol. Brain Res. 123, 81-90. doi: 10.1016/j.molbrainres.2004.01.003

Mesulam, M. M. (1981). A cortical network for directed attention and unilateral neglect. Ann. Neurol. 10, 309-325. doi: 10.1002/ana.410100402

Mesulam, M. M. (1995). Cholinergic pathways and the ascending reticular activating system of the human brain. Ann. N.Y. Acad. Sci. 757, 169-179.

Mesulam, M. M., Mufson, E. J., Levey, A. I., and Wainer, B. H. (1983a). Cholinergic innervation of cortex by the basal forebrain: cytochemistry and cortical connections of the septal area, diagonal band nuclei, nucleus basalis (substantia innominata), and hypothalamus in the rhesus monkey. J. Comp. Neurol. 214, 170-197. doi: 10.1002/cne.902140206

Mesulam, M. M., Mufson, E. J., Wainer, B. H., and Levey, A. I. (1983b). Central cholinergic pathways in the rat - an overview based on an alternative nomenclature (Ch1-Ch6). Neuroscience 10, 1185-1201. doi: 10.1016/03064522(83)90108-2

Mottron, L., Peretz, I., and Menard, E. (2000). Local and global processing of music in high-functioning persons with autism: beyond central coherence? J. Child Psychol. Psychatry 41, 1057-1065. doi: 10.1111/14697610.00693

Mundy, P., and Jarrold, W. (2010). Infant joint attention, neural networks and social cognition. Neural Netw. 23, 985-997. doi: 10.1016/j.neunet.2010.08.009

Mundy, P., and Neal, A. R. (2001). Neural plasticity, joint attention, and a transactional social-orienting model of autism. Int. Rev. Res. Ment. Retard. 23, 139-168. doi: 10.1016/S0074-7750(00)80009-9 
Murray, D., Lesser, M., and Lawson, W. (2005). Attention, monotropism and the diagnostic criteria for autism. Autism 9, 139-156. doi: 10.1177/1362361305051398

Naatanen, R., Paavilainen, P., Rinne, T., and Alho, K. (2007). The mismatch negativity (MMN) in basic research of central auditory processing: a review. Clin. Neurophysiol. 118, 2544-2590. doi: 10.1016/j.clinph.2007.04.026

Nakagawa, K., Otsuru, N., Inui, K., and Kakigi, R. (2013). Change-related auditory P50: a MEG study. Neuroimage.8, 00854-00859. doi: 10.1016/j.neuroimage. 2013.07.082

Natale, E., Marzi, C. A., Bricolo, E., Johannsen, L., and Karnath, H. O. (2007). Abnormally speeded saccades to ipsilesional targets in patients with spatial neglect. Neuropsychologia 45, 263-272. doi: 10.1016/j.neuropsychologia.2006. 07.008

Nicolson, R., Craven-Thuss, B., and Smith, J. (2006). A prospective, open-label trial of galantamine in autistic disorder. J. Child Adolesc. Psychopharmacol. 16, 621-629. doi: 10.1089/cap.2006.16.621

Oblak, A. L., Gibbs, T. T., and Blatt, G. J. (2010). Decreased GABA(B) receptors in the cingulate cortex and fusiform gyrus in autism. J. Neurochem. 114 1414-1423. doi: 10.1111/j.1471-4159.2010.06858.x

Oblak, A. L., Gibbs, T. T., and Blatt, G. J. (2011). Reduced GABAA receptors and benzodiazepine binding sites in the posterior cingulate cortex and fusiform gyrus in autism. Brain Res. 1380, 218-228. doi: 10.1016/j.brainres.2010. 09.021

O'Connor, K. (2012). Auditory processing in autism spectrum disorder: a review. Neurosci. Biobehav. Res. 36, 836-854. doi: 10.1016/j.neubiorev.2011.11.008

Ofek, E., and Pratt, H. (2004). Ear advantage and attention: an ERP study of auditory cued attention. Hear. Res. 189, 107-118. doi: 10.1016/S03785955(03)00392-7

O’Neill, M., and Jones, R. S. P. (1997). Sensory-perceptual abnormalities in autism: a case for more research? J. Autism Dev. Disord. 27, 283-293.

Oranje, B., Lahuis, B., van Engeland, H., van der Gaag, R. J., and Kemner, C. (2013). Sensory and sensorimotor gating in children with multiple complex developmental disorders (MCDD) and autism. Psychiatry Res. 206, 287-292. doi: 10.1016/j.psychres.2012.10.014

Orekhova, E. V., Butorina, A. V., Tsetlin, M. M., Novikova, S. I., Sokolov, P. A., Elam, M., et al. (2013). Auditory magnetic response to clicks in children and adults: its components, hemispheric lateralization and repetition suppression effect. Brain Topogr. 26, 410-427. doi: 10.1007/s10548-012-0262-x

Orekhova, E. V., Stroganova, T. A., Prokofiev, A., Nygren, G., Gillberg, C., and Elam, M. (2009). The right hemisphere fails to respond to temporal novelty in autism: evidence from an ERP study. Clin. Neurophysiol. 120, 520-529. doi: 10.1016/j.clinph.2008.12.034

Orekhova, E. V., Stroganova, T. A., Prokofyev, A. O., Nygren, G., Gillberg, C., and Elam, M. (2008). Sensory gating in young children with autism: relation to age, IQ, and EEG gamma oscillations. Neurosci. Lett. 434, 218-223. doi: 10.1016/j.neulet.2008.01.066

Orekhova, E. V., Tsetlin, M. M., Butorina, A. V., Novikova, S. I., Gratchev, V. V., Sokolov, P. A., et al. (2012). Auditory cortex responses to clicks and sensory modulation difficulties in children with autism spectrum disorders (ASD). PLoS ONE 7:6. doi: 10.1371/journal.pone.0039906

Ornitz, E. M. (1989). "Autism at the interface between sensory and information processing," in Autism: Nature, Diagnosis, and Treatment, ed G. Dawson (New York,NY: Guilford Press), 417.

Ornitz, E. M., and Ritvo, E. R. (1968). Perceptual inconstancy in early infantile autism. The syndrome of early infant autism and its variants including certain cases of childhood schizophrenia. Arch. Gen. Psychiatry 18, 76-98. doi: 10.1001/archpsyc.1968.01740010078010

Parasuraman, R., Greenwood, P. M., Kumar, R., and Fossella, J. (2005). Beyond heritability - neurotransmitter genes differentially modulate visuospatial attention and working memory. Psychol. Sci. 16, 200-207. doi: 10.1111/j.09567976.2005.00804.x

Perry, E. K., Lee, M. L. W., Martin-Ruiz, C. M., Court, J. A., Volsen, S. G., Merrit, J., et al. (2001). Cholinergic activity in autism: abnormalities in the cerebral cortex and basal forebrain. Am. J. Psychiatry 158, 1058-1066. doi: 10.1176/appi.ajp.158.7.1058

Ponton, C., Eggermont, J. J., Khosla, D., Kwong, B., and Don, M. (2002). Maturation of human central auditory system activity: separating auditory evoked potentials by dipole source modeling. Clin. Neurophysiol. 113, 407-420. doi: 10.1016/S1388-2457(01)00733-7
Posner, M. I., Walker, J. A., Friedrich, F. J., and Rafal, R. D. (1984). Effects of parietal injury on covert orienting of attention. J. Neurosci. 4, 1863-1874.

Ray, M. A., Graham, A. J., Lee, M., Perry, R. H., Court, J. A., and Perry, E. K. (2005) Neuronal nicotinic acetylcholine receptor subunits in autism: an immunohistochemical investigation in the thalamus. Neurobiol. Disabil. 19, 366-377. doi: 10.1016/j.nbd.2005.01.017

Renner, P., Klinger, L. G., and Klinger, M. R. (2006). Exogenous and endogenous attention orienting in Autism Spectrum disorders. Child Neuropsychol. 12, 361-382. doi: 10.1080/09297040600770753

Rimland, B. (1964). Infantile Autism; the Syndrome and its Implications for a Neural Theory of Behavior. New York, NY: Appleton-Century-Crofts.

Rissling, A. J., Park, S. H., Young, J. W., Rissling, M. B., Sugar, C. A., Sprock, J., et al. (2013). Demand and modality of directed attention modulate "preattentive" sensory processes in schizophrenia patients and nonpsychiatric controls. Schizophr. Res. 146, 326-335. doi: 10.1016/j.schres.2013.01.035

Riva, D., Bulgheroni, S., Aquino, D., Di Salle, F., Savoiardo, M., and Erbetta, A. (2011). Basal forebrain involvement in low-functioning autistic children: a voxel-based morphometry study. Am. J. Neuroradiol. 32, 1430-1435. doi: 10.3174/ajnr.A2527

Robbins, T. W. (1997). Arousal systems and attentional processes. Biol. Psychol. 45, 57-71. doi: 10.1016/S0301-0511(96)05222-2

Robinson RG. (1985). "Lateralized behavior and neurochemical consequences of unilateral brain injury in rats," in Cerebral Lateralization in Nonhuman Species Behavioral Biology, ed S. D. Glick (Orlando, FL: Academic Press), 135-156.

Rudnick, N., Koehler, C., Picciotto, M., and Siegel, S. (2009). Role of beta 2-containing nicotinic acetylcholine receptors in auditory eventrelated potentials. Psychopharmacology 202, 745-751. doi: 10.1007/s00213-0081358-6

Sarter, M., and Bruno, J. P. (2000). Cortical cholinergic inputs mediating arousal, attentional processing and dreaming: differential afferent regulation of the basal forebrain by telencephalic and brainstem afferents. Neuroscience 95, 933-952. doi: 10.1016/S0306-4522(99)00487-X

Sarter, M., Hasselmo, M. E., Bruno, J. P., and Givens, B. (2005). Unraveling the attentional functions of cortical cholinergic inputs: interactions between signaldriven and cognitive modulation of signal detection. Brain Res. Rev. 48, 98-111. doi: 10.1016/j.brainresrev.2004.08.006

Schoen, S. A., Miller, L. J., Brett-Green, B., and Hepburn, S. L. (2008). Psychophysiology of children with autism spectrum disorder. Res. Autism Spect. Disabil. 2, 417-429. doi: 10.1016/j.rasd.2007.09.002

Schröger, E., and Wolff, C. (1998). Attentional orienting and reorienting is indicated by human event-related brain potentials. Neuroreport 9, 3355-3358. doi: 10.1097/00001756-199810260-00003

Seri, S., Cerquiglini, A., Pisani, F., and Curatolo, P. (1999). Autism in tuberous sclerosis: evoked potential evidence for a deficit in auditory sensory processing. Clin. Neurophysiol. 110, 1825-1830. doi: 10.1016/S1388-2457(99)00137-6

Shaw, M. E., Hamalainen, M. S., and Gutschalk, A. (2013). How anatomical asymmetry of human auditory cortex can lead to a rightward bias in auditory evoked fields. Neuroimage. 74, 22-29. doi: 10.1016/j.neuroimage.2013.02.002

Skinner, R. D., Homma, Y., and Garcia-Rill, E. (2004). Arousal mechanisms related to posture and locomotion: 2. Ascending modulation. Prog. Brain Res. 143, 291-298. doi: 10.1016/S0079-6123(03)43028-8

Stiegler, L. N., and Davis, R. (2010). Understanding sound sensitivity in individuals with autism spectrum disorders. Focus Autism Dev. Disabil. 25, 67-75. doi: $10.1177 / 1088357610364530$

Stroganova, T. A., Kozunov, V. V., Posikera, I. N., Galuta, I. A., Gratchev, V. V., and Orekhova, E. V. (2013). Abnormal pre-attentive arousal in young children with autism spectrum disorder contributes to their atypical auditory behavior: an ERP study. PLoS ONE8 7:e69100. doi: 10.1371/journal.pone.0069100

Sturm, W., and Willmes, K. (2001). On the functional neuroanatomy of intrinsic and phasic alertness. Neuroimage 14, S76-S84. doi: 10.1006/nimg.2001.0839

Tarkka, I. M., Luukkainen-Markkula, R., Pitkanen, K., and Hamalainen, H. (2011). Alterations in visual and auditory processing in hemispatial neglect: an evoked potential follow-up study. Int. J. Psychophysiol. 79, 272-279. doi: 10.1016/j.ijpsycho.2010.11.002

Tecchio, F., Benassi, F., Zappasodi, F., Gialloreti, L. E., Palermo, M., Seri, S., et al. (2003). Auditory sensory processing in autism: a magnetoencephalographic study. Biol. Psychiatry 54, 647-654. doi: 10.1016/S0006-3223(03)00295-6

Teshiba, T. M., Ling, J., Ruhl, D. A., Bedrick, B. S., Pena, A., and Mayer, A. R. (2013). Evoked and intrinsic asymmetries during auditory attention: implications for 
the contralateral and neglect models of functioning. Cereb. Cortex 23, 560-569. doi: $10.1093 /$ cercor/bhs039

Thiel, C. M., and Fink, G. R. (2007). Visual and auditory alertness: modalityspecific and supramodal neural mechanisms and their modulation by nicotine. J. Neurophysiol. 97, 2758-2768. doi: 10.1152/jn.00017.2007

Townsend, J., Courchesne, E., and Egaas, B. (1996). Slowed orienting of covert visual-spatial attention in autism: specific deficits associated with cerebellar and parietal abnormality. Dev. Psychopathol. 8, 563-584. doi: $10.1017 /$ S0954579400007276

Travers, B. G., Adluru, N., Ennis, C., Tromp, D. P. M., Destiche, D., Doran, S., et al. (2012). Diffusion tensor imaging in autism spectrum disorder: a review. Autism Res. 5, 289-313. doi: 10.1002/aur.1243

Tsetlin, M. M., Pushina, N. P., Galuta, I. A., and Stroganova, T. A. (2008). Spatial asymmetry of frontal tasks performance in young boys with autism. Int. J. Psychophysiol. 69, 267. doi: 10.1016/j.ijpsycho.2008.05.209

Tudor, M. E., Hoffman, C. D., and Sweeney, D. P. (2013). Children with Autism: sleep problems and symptom severity. Focus Autism Other Dev. Disabil. 27, 254-262. doi: 10.1177/1088357612457989

van der Geest, J. N., Kemner, C., Camfferman, G., Verbaten, M. N., and van Engeland, H. (2001). Eye movements, visual attention, and autism: a saccadic reaction time study using the gap and overlap paradigm. Biol. Psychiatry 50, 614-619. doi: 10.1016/S0006-3223(01)01070-8

van Engeland, H. (1984). The electrodermal orienting response to auditive stimuli in autistic-children, normal-children, mentally-retarded children, and child psychiatric-patients. J. Autism Dev. Disord. 14, 261-279. doi: 10.1007/BF02409578

Vossel, S., Kukolja, J., Thimm, M., Thiel, C. M., and Fink, G. R. (2010). The effect of nicotine on visuospatial attention in chronic spatial neglect depends upon lesion location. J. Psychopharmacol. 24, 1357-1365. doi: 10.1177/0269881109105397

Wainwright-Sharp, J. A., and Bryson, S. E. (1993). Visual orienting deficits in high-functioning people with autism. J. Autism Dev. Disord. 23, 1-13. doi: 10.1007/BF01066415

Watson, L. R., Patten, E., Baranek, G. T., Poe, M., Boyd, B. A., Freuler, A., et al. (2011). Differential associations between sensory response patterns and language, social, and communication measures in children with autism or other developmental disabilities. J. Speech Lang. Hear. Res. 54, 1562-1576. doi: 10.1044/1092-4388(2011/10-0029)

White, P. M., and Yee, C. M. (2006). P50 sensitivity to physical and psychological state influences. Psychophysiology 43, 320-328. doi: 10.1111/j.14698986.2006.00408.x

Whitehouse, A. J. O., and Bishop, D. V. M. (2008). Do children with autism 'switch off' to speech sounds? An investigation using event-related potentials. Dev. Sci. 11, 516-524. doi: 10.1111/j.1467-7687.2008.00697.x

Wiggins, L. D., Robins, D. L., Bakeman, R., and Adamson, L. B. (2009). Brief report: sensory abnormalities as distinguishing symptoms of autism spectrum disorders in young children. J. Autism Dev. Disord. 39, 1087-1091. doi: 10.1007/s10803-009-0711-x

Williams, J. H. G., Whiten, A., Suddendorf, T., and Perrett, D. I. (2001). Imitation, mirror neurons and autism. Neurosci. Biobehav. Rev. 25, 287-295. doi: 10.1016/S0149-7634(01)00014-8

Witte, E. A., Davidson, M. C., and Marrocco, R. T. (1997). Effects of altering brain cholinergic activity on covert orienting of attention: comparison of monkey and human performance. Psychopharmacology 132, 324-334. doi: $10.1007 / \mathrm{s} 002130050352$

Woods, A. J., Mennemeier, M., Garcia-Rill, E., Huitt, T., Chelette, K. C., McCullough, G., et al. (2012). Improvement in arousal, visual neglect, and perception of stimulus intensity following cold pressor stimulation. Neurocase 18, 115-122. doi: 10.1080/13554794.2011. 568498

Yee, C. M., Williams, T. J., White, P. M., Nuechterlein, K. H., Ames, D., and Subotnik, K. L. (2010). Attentional modulation of the p50 suppression deficit in recent-onset and chronic schizophrenia. J. Abnorm. Psychol. 119, 31-39. doi: $10.1037 / \mathrm{a} 0018265$

Yucel, G., Petty, C., McCarthy, G., and Belger, A. (2005). Visual task complexity modulates the brain's response to unattended auditory novelty. Neuroreport 16 , 1031-1036. doi: 10.1097/00001756-200507130-00001

Yvert, B., Crouzeix, A., Bertrand, O., Seither-Preisler, A., and Pantev, C. (2001). Multiple supratemporal sources of magnetic and electric auditory evoked middle latency components in humans. Cereb. Cortex 11, 411-423. doi: 10.1093/cercor/11.5.411

Zwaigenbaum, L., Bryson, S., Rogers, T., Roberts, W., Brian, J., and Szatmari, P. (2005). Behavioral manifestations of autism in the first year of life. Int. J. Dev. Neurosci. 23, 143-152. doi: 10.1016/j.ijdevneu.2004.05.001

Conflict of Interest Statement: The authors declare that the research was conducted in the absence of any commercial or financial relationships that could be construed as a potential conflict of interest.

Received: 10 November 2013; accepted: 17 January 2014; published online: 06 February 2014.

Citation: Orekhova EV and Stroganova TA (2014) Arousal and attention re-orienting in autism spectrum disorders: evidence from auditory event-related potentials. Front. Hum. Neurosci. 8:34. doi: 10.3389/fnhum.2014.00034

This article was submitted to the journal Frontiers in Human Neuroscience. Copyright (c) 2014 Orekhova and Stroganova. This is an open-access article distributed under the terms of the Creative Commons Attribution License (CC BY). The use, distribution or reproduction in other forums is permitted, provided the original author(s) or licensor are credited and that the original publication in this journal is cited, in accordance with accepted academic practice. No use, distribution or reproduction is permitted which does not comply with these terms. 